SB 413

. C55 $\$ 6$

Copy 1

Manual

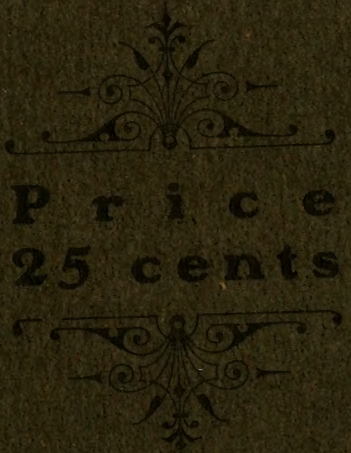

Nathan Smith \& Son Adrian, Mich. 


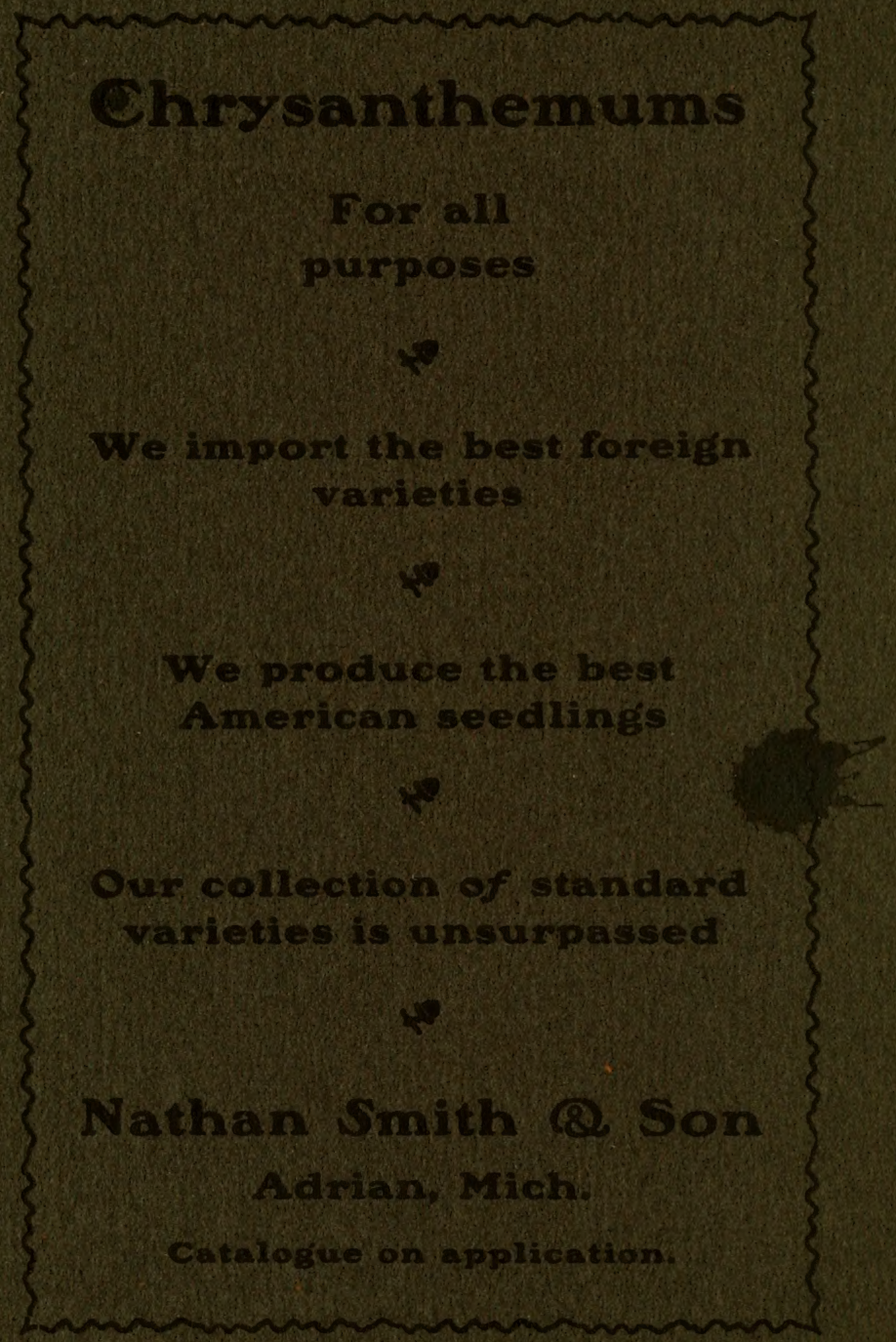




\section{SMITH'S}

\section{CHRYSANTHEMUM MANUAL.}

BY

ELMER D. SMITH

WHO HAS GIVEN HIS UNDIVIDED ATTENTION FOR TWENTY YEARS TO THE IMPROVEMENT OF THE CHRYSANTHEMUM AND ITS CULTURE IN DETAIL.

\section{PRICE 25 CENTS.}

Copyright, 1904, by Elmer D. Smith. 


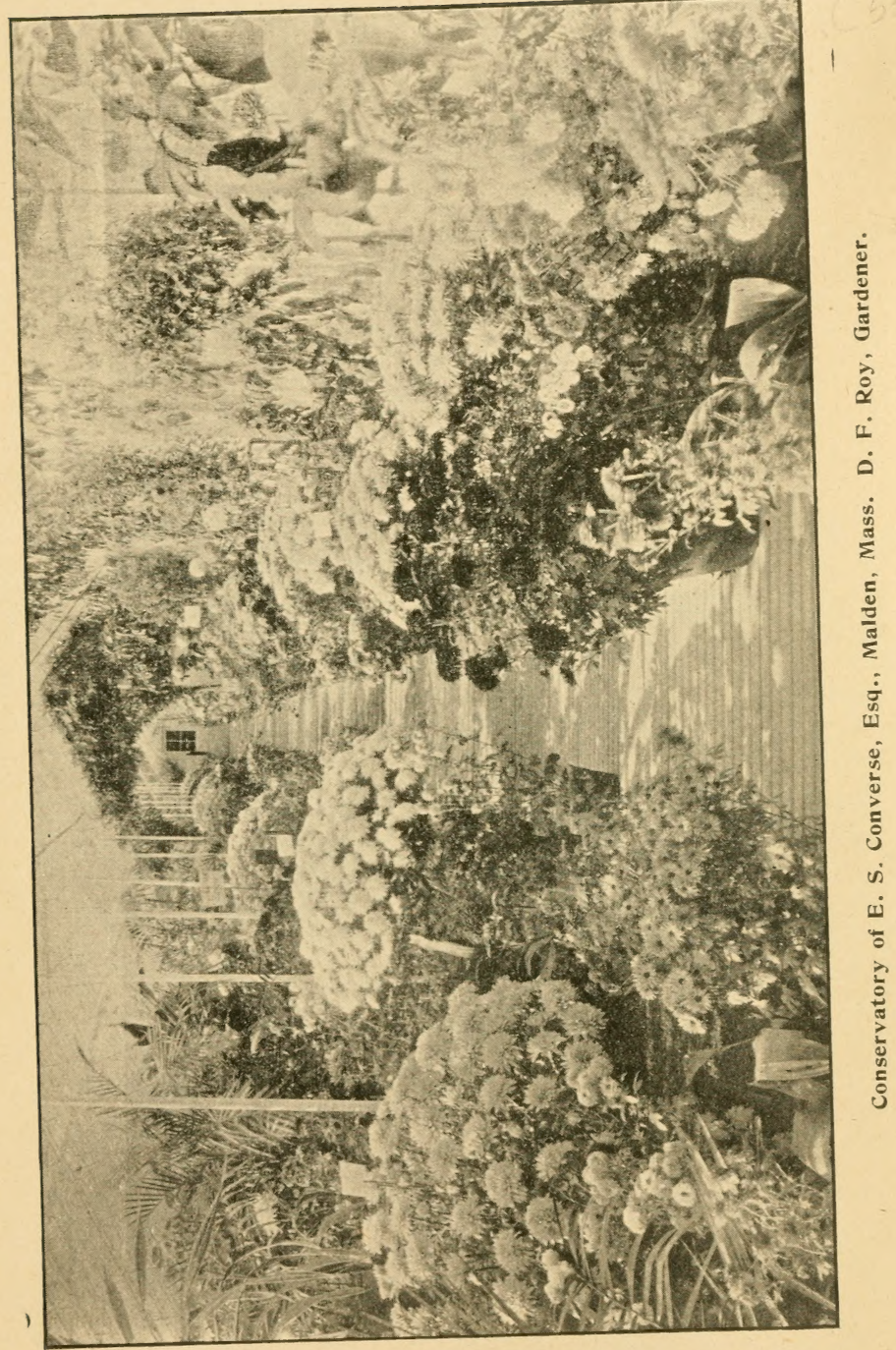




\section{CONTENTS.}

INTRODUCTION

THORORY

CHAPTER II.-STOCK PLANTS $\ldots \ldots \ldots \ldots \ldots \ldots \ldots \ldots \ldots \ldots \ldots \ldots \ldots \ldots, 8_{8}$

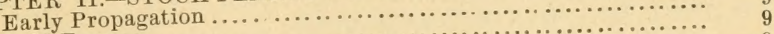

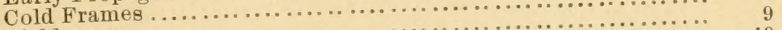

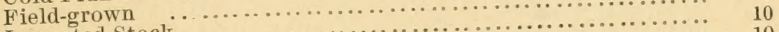

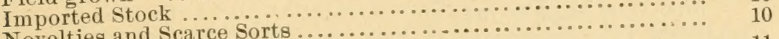

Novelties and Scarce Sorts ............................... 11

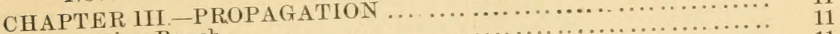

Cutting Bench .............................................. 11

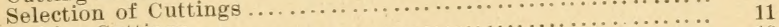

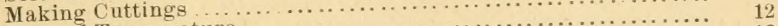

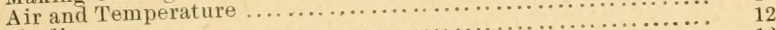

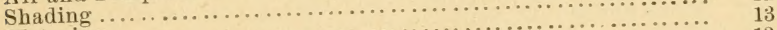

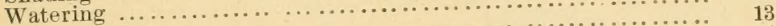

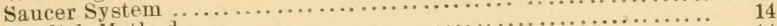

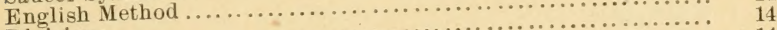

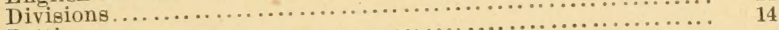

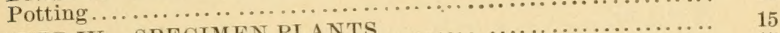

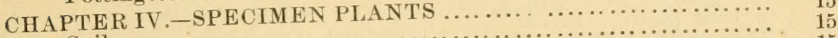

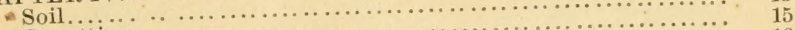

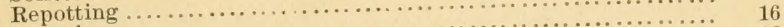

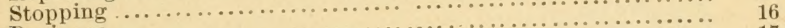

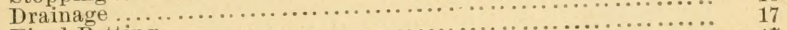

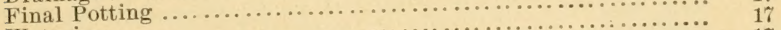

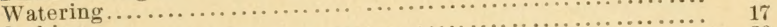

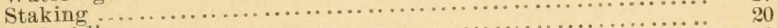

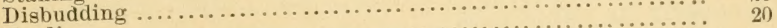

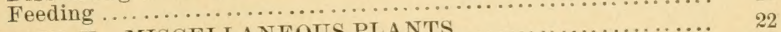

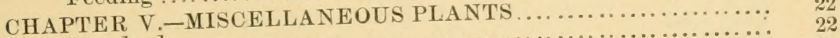

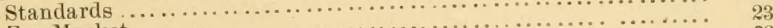

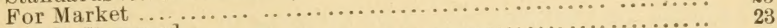

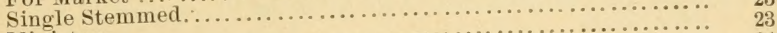

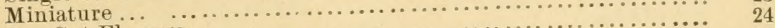

For Cut Flowers ......................................... 24

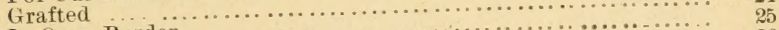

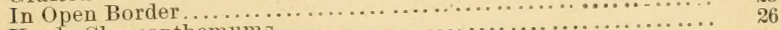

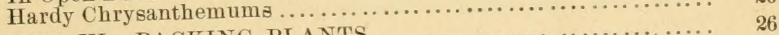

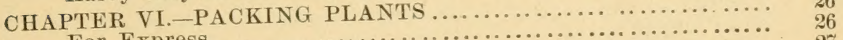

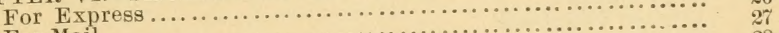

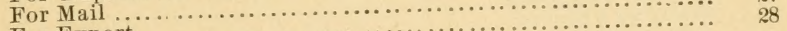

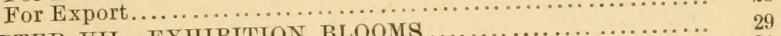

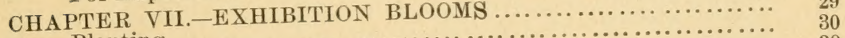

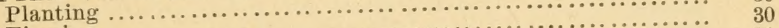

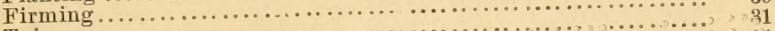

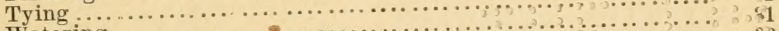

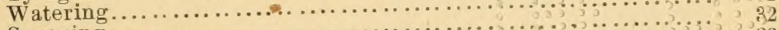

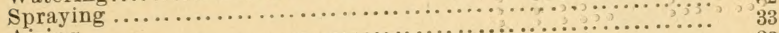

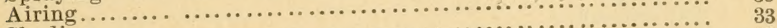

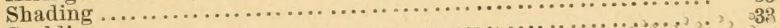

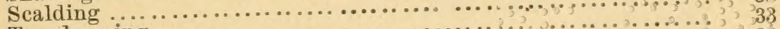

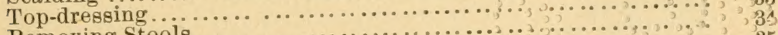

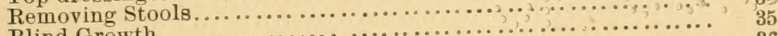

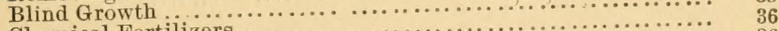

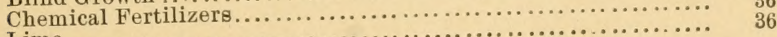

Lime 


\section{CONTENTS:}

CHAPTER VII.-Continued. Page.

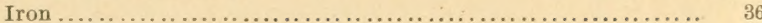

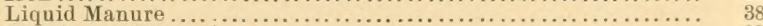

Burning and Damping ...................................... 38

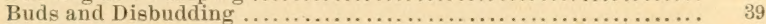

Taking the Buds ........................................ 40

Stopping $\ldots \ldots \ldots \ldots \ldots \ldots \ldots \ldots \ldots \ldots \ldots \ldots \ldots \ldots \ldots \ldots \ldots \ldots \ldots \ldots, 43$

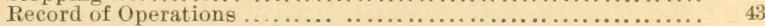

CHAPTER VIII.-EXHIBITION BLOOMS .................... 43

Grown out-of-doors.................................. 43

A ustralian Method ........................................... 45

Shelter or Snug Harbor ................................. 48

CHAPTER IX,-COMMERCIAL FLOWERS .................. 48

Feeding ............................................ 48

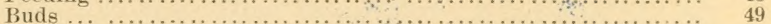

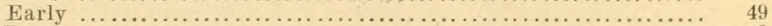

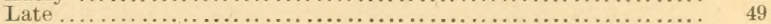

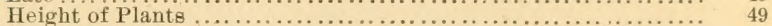

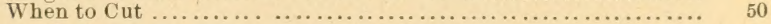

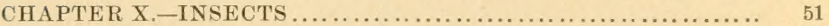

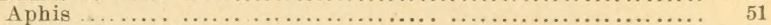

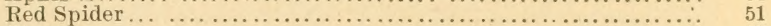

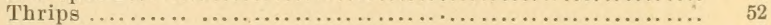

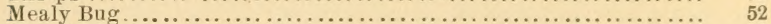

Grasshoppers ..................................... 52

Tarnished Plant Bug......................................... 52

Corythuca Gossypi............................................. 54

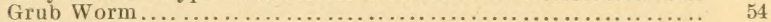

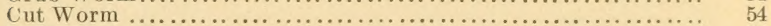

Lady Bird .......................................... 54

Golden Eye ............................................. 54

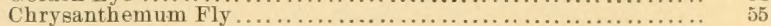

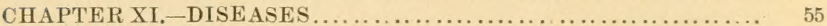

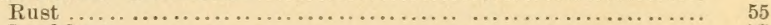

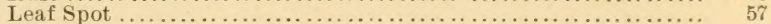

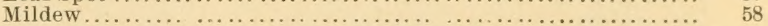

CHAPTER XII.-SEEDLINGS AND SPORTS . . . . . . $\ldots \ldots \ldots \ldots \ldots \ldots$

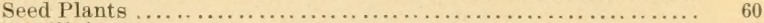

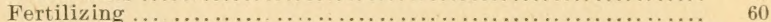

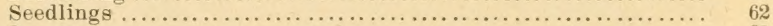

Sports.......... $\quad \ldots \ldots \ldots \ldots \ldots \ldots \ldots \ldots \ldots \ldots \ldots \ldots \ldots \ldots, 63$

CHAPTER XIII.-PREPARING EXHIBITS ................. 64

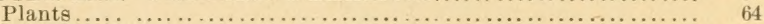

Cut Flowers ......................................... 65

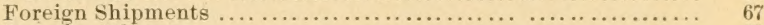

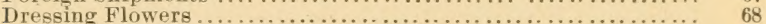

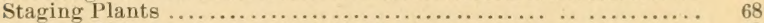

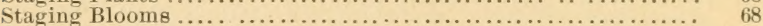

Boards $\ldots \ldots \ldots \ldots \ldots \ldots \ldots \ldots \ldots \ldots \ldots \ldots \ldots \ldots \ldots \ldots \ldots \ldots \ldots, 7_{0}$

Vases................................................. $7_{0}$

GHEPTER XIV

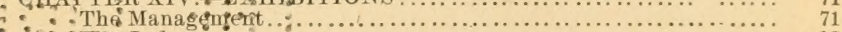

"Trle Judge

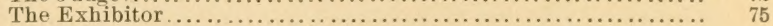

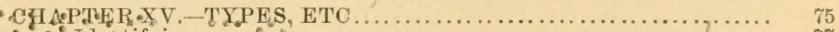

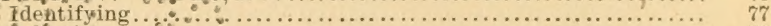

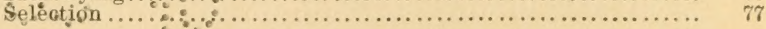




\section{ILLUSTRATIONS.}

Page.

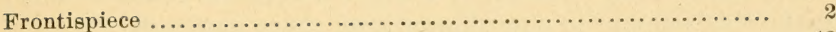

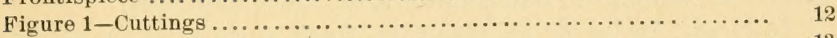

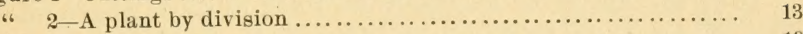

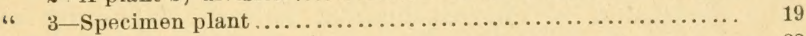

" 4-Market plant................................... 22

"6 5--Bench tied to wire. ................................ 31

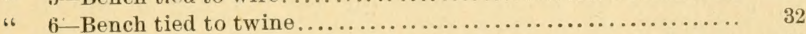

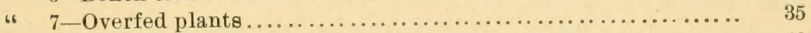

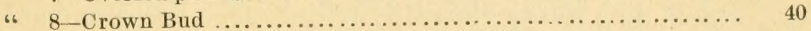

" 9 -Terminal Bud .................................. 41

" 10 -Bloom from Crown ............................... 42

"، 11 -Shelter or Snug Harbor .......................... 47

" 12 -Bloom from Terminal........................... 48

" 13-Comparative Height from Crown and Terminal .......... 50

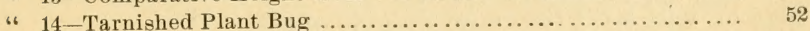

"6 15-Depredation of the Tarnished Plant Bug ............... 53

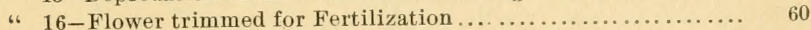

" 17 -Pistillate and Staminate Florets ...................... 61

، 18 -A Collection properly staged ...................... 69 


\section{INTRODUCTION.}

During the past twenty years, I have devoted much time and energy to the cultivation and improvement of the Chrysanthemum and have received many inquiries from those desirous of gaining knowledge on this subject. Confronted with these facts, and realizing the urgent need for a complete, as well as practical treatise, at a price within the reach of all, I make this attempt in compliance with these demands.

It is my desire to concisely set forth in these pages all details pertaining to Chrysanthemum culture, beginning with stock plants, treating the many branches, through each stage of development, up to and including the staging of plants and cut blooms.

Most of the works upon this subject have been confined to methods practical only to florists, having every facility necessary to successful culture.

The amateur, growing a few plants for pleasure and eager for better results, has been entirely overlooked. It is hoped this booklet will meet the requirements of all.

There is no plant which responds more freely to careful attention than the Chrysanthemum. The whole secret of success lies in prompt attention to details and when these are thoroughly understood and executed, we may expect a generous reward.

\section{ELMER D. SMITH,}

Member of the Chrysanthemum Society of America, The National Chrysanthemum Society of England, and Society Francaise des Chrysanthemistes. 


\section{SIMITH'S}

\section{CHRYSANTHEMUM MANUAL.}

\section{CHAPTER I.}

\section{HISTORY.}

The derivation of the word Chrysanthemum is from the Greek words Chrysos, gold,-and Anthemon, a flower. It is not easy to say how long the Chrysanthemum has been known to mankind, but undoubtedly over 2000 years have elapsed since it was first known in the Celestial Empire.

In Japan its cultivation can be traced back over 700 years. Breynius, in 1689, was the first European to mention the Chrysanthemum under the name of Matricaria Japonica Maxima. M. Pierre Louis Blancard introduced the first large flowering varieties into England in 1789 and the following year they were flowered and named. Mr. John Salter was one of the earliest English hybridizers, and produced many wonderful varieties from 1838 to 1848 .

As near as can be ascertained, it has been seventy years since they were introduced into America. Dr. H. P. Walcott is credited as being the first person in this country to raise new varieties from seed, which he did as early as 1879 . The work of hybridization was taken up by Wm. K. Harris and John Thorpe early in the 80 's.

Their efforts were crowned with great success both originating many new and startling varieties. These results were incentive to others until the zenith was reached in 1894 , when 163 new varieties were offered for sale, many of which were inferior to those then in commerce. This condition caused 
many to be skeptical, doubting the merits of the so-called novelties, until fully tested.

In the meantime, John Thorpe had conceived the idea of organizing a society to protect the interests and also promote the development of this flower which was fast gaining popularity. In 1890, at Buffalo the organization now known as the Chrysanthemum Society of America, was established. In 1894 this society appointed committees composed of experts to meet during the following season at Chicago, Cincinnati, Philadelphia, New York and Boston, to inspect seedlings and sports. These committees have been continued from year to year, awarding first-class certificates to the deserving ones.

Such action brought the varieties certificated into prominence, and those which failed to meet their commendation were so little sought after as to be unprofitable, and many discontinued hybridizing. Up to the present the Society has certificated 265 varieties, most of which were of American origin; although a few importations have been thus favored.

The first exhibition given by the C. S. A. was in November 1902 , under the auspices of the Horticultural Society of Chicago. Last year it was held at New York, in co-operation with the American Institute. The next exhibition will be held November 3rd to 6th, 1904, at Boston, with the Massachusetts Horticultural Society.

\section{CHAPTER II.}

STOCK PLANTS.

At the close of the flowering season the old plants must be saved for stock, from which to propagate young plants for another year's use. Each grower must decide how many will be required and provide the most suitable situation for their maintenance.

The amateur will need only two or three of a kind, while the commercial florist may need several thousand of the most popular sorts to meet his demand. Some varieties are more susceptible of being increased than others, making cuttings abundantly and rooting freely. 
Those who propagate for their own use only should keep the plants in a low temperature, just above freezing and even a few degrees of frost will not materially injure them. They thrive best when kept on the dry side during the dark days of winter, at which time they are rather inactive. The florist who requires quantities for early distribution, will be obliged to grive higher temperature, about 50 degrees; and their needs for water should be carefully considered, avoiding if possible too abundant and frequent use, as such a course tends to weaken the plants, thus giving sickly cuttings.

Early Propurytion... Stock plants for early propagation are generally planted on greenhouse benches, producing surcessive crops of cuttings. With the new and scarce sorts it is sometimes advisable to take cuttings even as early as September or October, and as soon as rooted, these are planted in shallow boxes or upon the bench. When large enough the tops are taken off as cuttings. This induces the plants to make new breaks, which are used for cuttings when of suitable size.

Cold Frames.-The cold frame system is most practical for those who do not have greenhouses, and the wholesale florist who needs large quantities of plants for June and July delivery, will find them equally serviceable.

In the construction of cold frames there is no objection to excavating one or two feet, provided ample drainage can be secured; otherwise it is best to make board frames and plant stock on the level or slightly elerated so that no surplus moisture will remain about the roots. Stock thus stored should be protected by covering the frames with boards. To prevent continual freezing and thawing, these frames may be covered with course manure or litter. Most varieties are not injured by freezing provided they are kept in this condition until spring.

Field Grown.-Field grown stock is in every way more satisfactory than that which has produced blooms under glass. They appear to possess more vigor and give successive crops with greater rapidity. These may be handled in cold frames 
as previously mentioned, or removed to greenhouse when early propagation is necessary.

Importal stock. - Those importing foreign varieties often find them in very poor condition when unpacked. This is not to be wondered at when we consider they are two to six weeks in transit. They are generally packed in dry cocoanut fiber, and when taken from the box look like dry sticks. It is only by the utmost vigilance and eare that such plants are nursed into actirity. Immerse them into tepid water for a few hours to plump the wood and roots.

After removing all lifeless growth, pot them in light soil, using as small a pot as will accommodate the roots. It should be the aim to induce root growth as soon as possible and to do this plunge them into a close case which is provided with gentle bottom heat, about 70 degrees will suffice. See that the material in which they are plunged is kept on the dry side and use water rather sparingly until they begin to grow freely. They should be looked to several times each day and if the plants or soil show signs of fungus, ventilation must be given, for such conditions, if not promptly checked, are fatal. It is often wise to remove the cuttings when quite small and root them, especially if the old plants are weak or show signs of decay.

By taking this course it is possible to establish a small plant upon its own root, which would otherwise be lost if allowed to remain until the old plant had gained vigor.

Norelties and Scarce Sorts.-Novelties and scarce sorts are often bought in limited quantity to propagate from. The best results are olstained by planting these young plants into flats (shallow boxes), or upon the bench in shallow soil. As soon as they show signs of growth, the tops are taken as cuttings and the plants are treated thereafter same as stock plants. 


\section{CHAPTER III.}

\section{PIROPAGATION.}

Assuming the plants have been cared for and are in proper condition, the next step is the propagation of young plants. This is best done with soft wood cuttings or divisions, the former however, are generally used.

Cutting Bench.-The cutting bench is simply a table or bench constructed to hold three or four inches of material into which the cuttings may be inserted. Clean washed sand is considered the best material, but when unavailable, coke, brick or stone finely crushed and screened will give very satisfactory results. After the bench is filled with sand it should be pounded as firm as possible and given a thorough watering when it is ready for use. In preparing these benches see that all material is clean and free from decayine matter and to this end a coat of whitewash will be beneficial.

Selection of Cuttings.-In the selection of cuttings it is generally conceded the strong and vigorous are the best, although on several occasions we have had excellent results from those grown in the shade and drawn with heat until they were the size of knitting needles. Stock properly handled will give good cuttings, and would take weak ones only when absolutely necessary.

Miking Cuttings.-These are cut from an inch to three inches long, removing the lower and shortening the tips of the larger leaves. See Fig. 1.

With a knife make a cut in the sand $3 / 4$ in. deep, or more, according to length of cuttings, inserting close together and firm the sand well about them. Give the whole a liberal watering and keep constantly wet until rooted, which will require six to twelve days.

To insure the largest percentage the cuttings should be moderately soft at the time they are removed from the plant. Single eye cuttings of new and scarce sorts may be used when necessary. These are fastened to toothpicks with fine stemming wire, allowing half of the tooth-pick to extend below the 
end of the cutting, which should firmly rest on the sand when inserted in the bed. See C. Fig. 1. It requires more time to produce good plants by this system than where fair sized cuttings are taken, but is often of service where stock is limited.

Air and Temperature.-The propagating house should be well aired and as far as possible the atmospheric temperature should not exceed i.) degrees, with a bottom heat of 10 degrees higher.

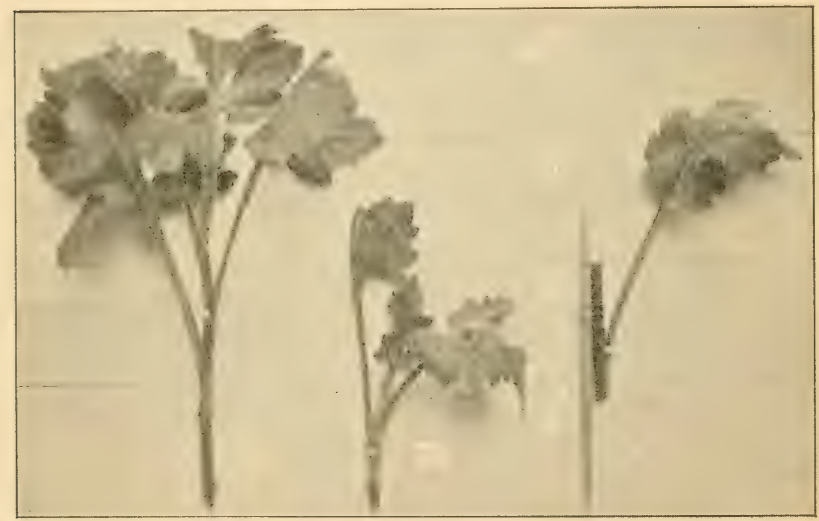

Fig I, Cuttings-A, long; $B$, short; $\mathcal{C}$, single eye.

The Chrysanthemum is so susceptible of being rooted that no fast rule can be given. They may be struck in a temperature as low as 40 , and as high as 80 degrees, but if the former is adopted they root very slowly and many varieties become hard and refuse to root. On the other hand if too high temperature is used cutting bench fungus is liable to set in and ruin the crop.

Shading.-As the season advances and the out-door temperature rises, it is impossibe to maintain 55 degrees and the soft cuttings are very much inclined to flag or wilt. For 
February and March propagation, tack burlap on the underside of the glass to exclucle the greater portion of sunlight, and as the season advances apply whitewash on outside of the glass. By such protection the cuttings can generally be rooted in fair condition up to 1st of May. After this date cover the propagating beds with newspapers to further protect them from the extreme heat and give copious watering two or three times a day. Let the condition of cuttings be index for shading but use every precaution necessary to prevent wilting, exclude light by covering and damp the walks to lower the temperature.

Watering.-It is very important that cuttings should never get dry, for under such conditions the end inserted in the sand becomes brown and hardened and will not take up water in sufficient quantity to revive the foliage, thus becoming worthless. Many of the wholesale florists propagate chrysanthemums the year round, although the bulk are struck during the months of March, April and May.

Saucer System.-Those who wish to propagate a few plants and are not favored with the facilities of the greenhouse,

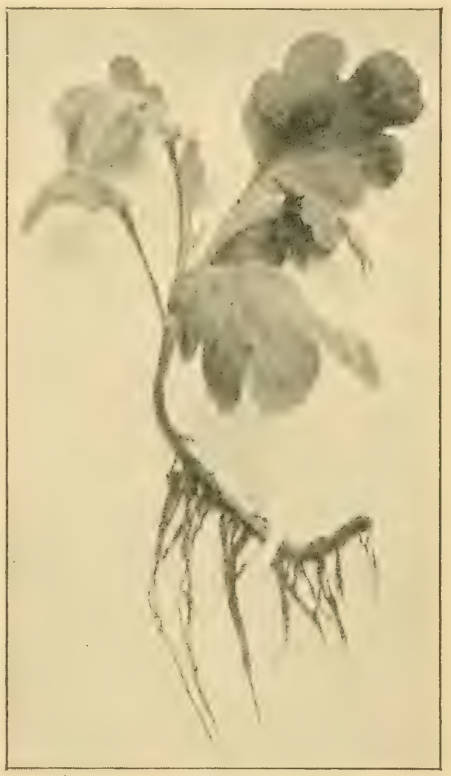

Fig. 2. A plant by division. may use shallow boxes or any dish that will hold a few inches of sand. A dozen or more cuttings may be inserted at a time by adopting the "Saucer System" given by Peter Henderson in his work "Practi- 
cal Floral Culture," which is as follows: "It is called the Saucer System because saucers or plates are used to hold the sand in which the cuttings are placed. The sand is put in to a depth of an inch or so and the cuttings are inserted in it close enough to touch each other. The sand is then watered until it becomes the condition of mud, and placed on the window sill fully exposed to the sun. But one condition is essential to success, until the cuttings become rooted the sand must be continually saturated and kept in the condition of mud; if once allowed to dry up, the whole operation will be defeated."

English Method.-The English method may be of service to the amateur and is as follows: Insert three or four cuttings around the edge of a four-inch pot that has been previously filled with light soil, consisting of loam, sand and leaf mould, equal parts. These are placed into a close frame and given same attention as suggested for Imported Stock, pg. 10.

Divisions. - In localities where the plants remain out-of-doors over winter without injury, they can be increased by removing the sprouts or stools that have sprung up from the base of the old plant. As these stools come into active growth, roots are formed near the surface of the soil, and may then be removed and replanted or potted as desired. Often such pieces are difficult to pot owing to the long crooked stems. These are removed as shown in Fig. 2, leaving a few roots to establish the young plant. New varieties are generally produced by seeds which are fully treated in Chapter XII.

Potting.-Cuttings should not remain in the bench after the roots are half an inch long, as they are potted easier and better in every way than when allowed to remain until the roots are further developed.

The soil should not be dry, but moist enough to remain intact when squeezed in the hand, and on the other hand not be muddy. Cuttirgs are usually potted in small pots, the two-inch size being ample. Put sufficient soil in the bottom of the pot, so that the base of the cutting will be about $3 / 4$ of an inch below the surface, hold cutting in center of pot with one hand and fill in with the other. Firm the soil with thumb or 
fingers enough to keep the cutting upright and be sure to leave sufficient space for water, which should be applied liberally without delay.

\section{CHAPTER IV.}

\section{SPECIMEN PLANTS.}

Cuttings may be taken any time from January 15th, to March 15, but those struck in February give best results. As soon as rooted they are potted in $2 \mathrm{in.} \mathrm{pots} \mathrm{using} \mathrm{light} \mathrm{soil} \mathrm{and}$ placed in a cool, airy house and as near the glass as possible. If given proper attention, such plants will make large specimens from three to six feet high, and nearly as wide by flowering time. In the course of a week or ten days the roots will push to the side of the pot and will need shifting into the next larger size.

Soil.-There are many ideas as to what soil is best suited for chrysanthemums. Each expert has a way of his own,in preparing the soil, but as equally good results have been obtained under varied conditions, it is safe to conclude that the compost employed has little to do with results, provided it contains sufficient food to nourish the plant and the cultivator is a close observer, considering the conditions under which they are grown.

All concede that fresh cut sod piled late the preceeding fall with one-fourth its bulk of decomposed manure, makes an excellent compost.

Repotting.-Turn out the plants, take them with the left hand and place in the new pot (which is generally an inch larger than the one from which they were removed) so that the ball is a half an inch below the rim of the pot and the plant stands in the center. While held in this position, fill in sufficient soil and firm gently with a stick around the pot, until it is filled level with the original ball of earth. If the soil is retaintive and rather wet, the ramming process can be carried to extremes, but if of a light nature, it should be made 
rather firm, and when the final potting is done, it can scarcely be carried to excess.

Stopping.-The term "stopping" means pinching out the center of a shoot, and the object is, to force the plant to make several growths instead of the present one.

When the plants are established in four-inch pots they are generally from four to six inches high, and at this stage the pinching and stopping begins. This should be done a few days before repotting or deferred until after the plants have made roots into the new soil. This induces the plant to make several side shoots, and as soon as these have attained four or five inches in length they are again stopped. This work is repeated throughout the season up to August 10th. Some of the varieties may be stopped a trifle later, but each cultivator must know the flowering time of those under his care. The early varieties set bud earlier, and it may be wise to discontinue stopping some of these as early as August 1st. By April 1st to 15th the plants should be in full vigor and ready to shift into six-inch pots, with this potting use a richer soil by adding to the ordinary compost a dusting of wood ashes, and a little pulverized sheep manure. The latter should be used in very small proportions.

Drainage.-Free drainage is essential and would recommend charcoal to be used for such varieties as are liable to burn. Coal ashes is also a good material for this purpose and may be used as advantageously as broken crocks. Put firmly when the soil is light, and loosely when the soil is heary. At this stage the plants are carefully observed, their manner of growth noted, also tendency to break, and liability to disease. The grood as well as the bad points are almost certain to appear during April and only surh as promise well are shifted up to the largest sizes. Some of the varieties have the habit of setting premature buds at this stage of growth. Such conditions are unfavorable to the production of fine specimens, although the greater majority will outgrow the defect after this blooming period has passed. 
From 1st to 15th of May another shift will be necessary and this time into seven or eight-inch pots, according to the varieties. The weaker growing should be put into the smaller size, and the stronger ones into the largest. As the plants at this season begin to assume some size and owing to the higher temperature which prevails, the watering will need constant attention. In repotting at this time the plants should be set low enough in the pot to allow ample space for water, not less than an inch, but better an inch and a half, to hold sufficient water to saturate all parts of the soil.

Final Potting. - The final potting occurs from June 1st to 15th; for this give a richer compost, using a rather rough open soil containing a large portion of broken, half decomposed sodk. This must be packed more firmly in the pots. A close, heavy loam is bad, but if it must be used, it should be only lightly firmed; sufficient sharp sand may be used to keep the water passing out freely.

Watering.-All experts agree that the plants should never suffer for want of water, and consider it one of the most important details in all stages of development. On the other hand it is very important that the drainage be ample so that the water passes through freely, thus preventing stagnation, a condition condusive to disease, which will finally result in failure.

It sometimes occurs that the exact condition of plants in pots is not fully indicated by the appearance of the soil. A very accurate course to follow is to rap the pots with the knuckles or a stick, those that are wet have a duil sound, and those that are dry a hollow sound. A few days trial will teach the operator to detect the difference in sound at an instance.

Staking.-During August many of the plants will have attained considerable height, even though they have been stopped every few days. Those which are inclined to make too dense growth should be provicled. with a few stakes and the branches gradually tied out to the desired form, thus making a foundation to build upon later. These stakes will need to be 
removed later on, and replaced by longer ones, when it is determined how tall the plants are likely to grow.

Early in September it will be necessary to consider the final staking and tying out. The main object in specimen plants is to develop as many growing shoots as possible before the middle of August, arranging them so as to keep the plants even and regular in form. How this is to be done is somewhat a matter of taste, but it is easier to do it all at once as more shapely plants can be formed. If the plants are desired for exhibition purposes and are to be transported some distance to the exhibition hall, the stake system is preferable to that of the wire frame, the advantage being that plants tied to stakes can be drawn together so there will be no friction, and at the same time occupy much less space.

The best course to follow in the matter of staking and tying largly depends upon the size and form to which they are to be trained. The Japanese growers shape their plants into many artistic designs, such as crosses, fans, boats, parasols, etc. When such forms are to be perfected it is necessary to make a temporary frame-work of wire or stakes to which the shoots may be tied out int, the form desired, and this should be provided lie. fore the plants attain any great size. The forms generally adopted for exhibition groups are round and, slightly elevated in the center, as shown in Fig. 3, page 19, and are grown all sizes from three to six feet in beight and nearly as wide.

The operation of staking is simply placing stakes into the soil, the outer ones at such an angle as to bring the branches in the desired position to give the plant the recuired diameter. Additional stakes are supplimented to hold the inner branches in position.

The best material for tying is silkaline, which does not slip, being soft, dues not injure the shoots and as its color is green, is not so conspicuous as where white string is used. 


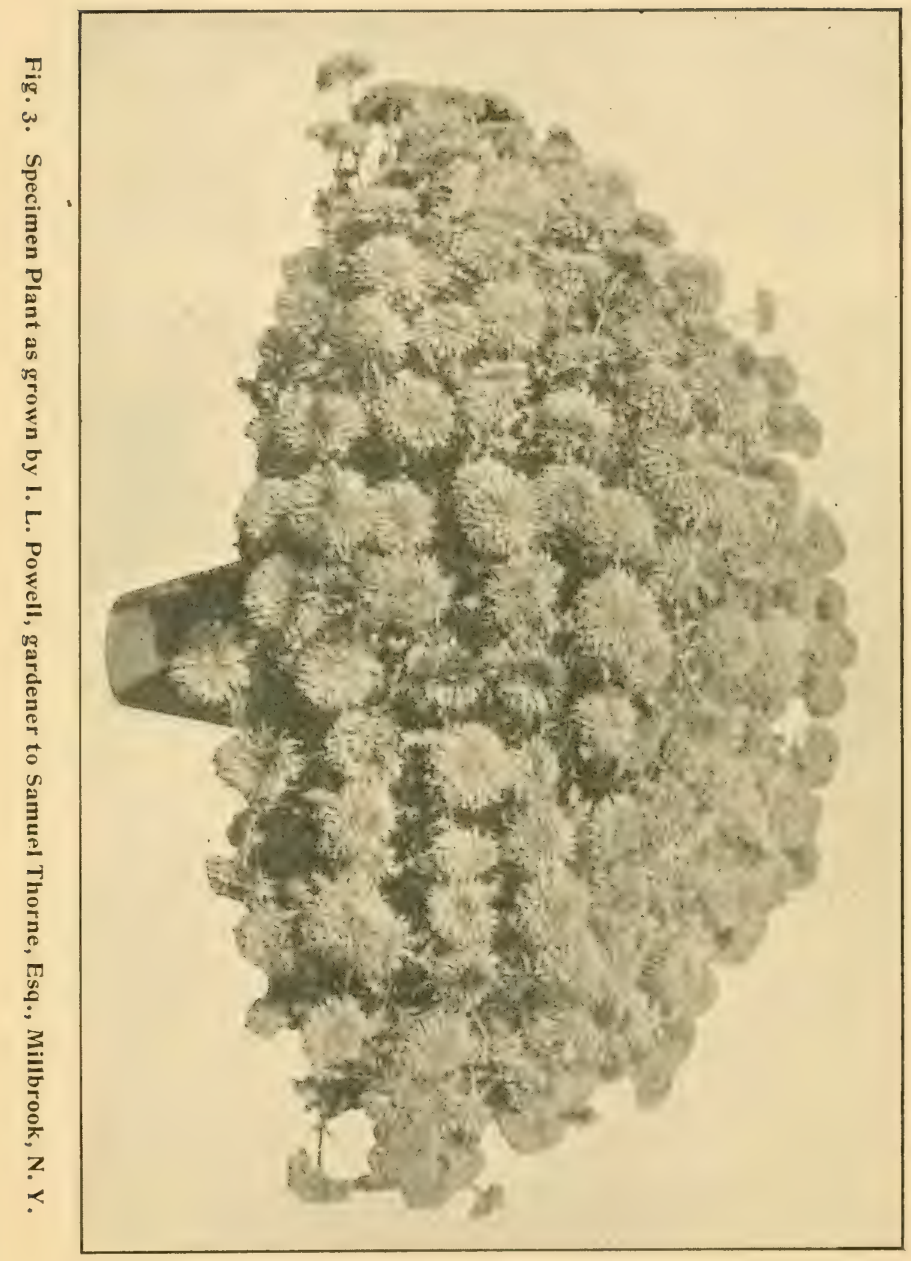


Tying out should not be left too long, in fact, it should be done every few days. There are always some overgrown vigorous shoots which are lifficult to accommodate, but while supple they will bend easily. A bad hole or open space can sometimes be filled by these strong growths, bending them down and tying securely. When specimen plants are grown for conservatory decoration, or where they can be practically transported to the exhitition ball, the wire frames may be used.

When wire frames are used, tie as many shoots as possible to the lower part of the frame, as the greatest danger is conjestion at the top.

Disbudding.-The operation of disbudding will need attention early in September. The early varieties setting buds first and the later ones following, according to the natural flowering time. For early exhibitions say the 1st of November, buds should be prominent by September 15, and showing color four weeks later. At least three weeks are required after they show color until maturity.

Generally all the specimen plants produce terminal buds; each shoot bearing a cluster at the extremity, which is disbudded so as to leave only one bud to each and this the center one. In this way the flowers are uniform in size, and if the plant has been well trained and tied out thest'individual blooms will nearly touch each other.

After setting buds the plants will begin sending out suckers from the roots in all directions, which if allowed to remain rob the buds of the nourishment which has been provided for their development. These should be removed at once and this operation repeated as often as they appear, as well as any lateral growths which may start from the shoots.

Feeding.-The application of stimulants requires careful consideration and should be entrusted only to persons of judgment and discretion. With the roots so much confined in the pots, even more care is required than where the bench system is employed in the production of cut blooms.

The pots must be filled with roots and the drainage perfectly free to begin with. If cow manure is used as a top dress- 
ing it would be best to dry it first and afterwards break into small pieces. This acts as a mulch and fertilizer at the same time. As a safe and lasting stimulant, sheep manure is preferred, which should be applied in the form of a top dressing, adding a little sandy loam to keep it open. Li(yuid manure may also be used if the plant continues healthy, applying once a week at first and twice or three times a week later. Sulphate of amonium and nitrate of soda are sometimes used with wonderful results, but must be applied with dircretion.

From the time the buds are set success depends very much upon the judicious use of fertilizers, either in liquid form or a top dressing. Some plants will take lipuid manure in liberal amounts, others if so treated are easily injured. Over-feeding shows itself in yellow stunted foliage. When this occurs use clear water and let them get as dry as they can with safety.

The grower needs to be acquainted with the plants as with individuals; it is a matter of experience and when carefully done may be continued until the buds show color. It is, however, worthy to note that pink and red varieties, including bronze, show lack of color and also burn easily if feeding is continued too long. ('lay's fertilizer is a good manure and perfectly safe to use either as a liquid or top dressing mixed with a little loam. Soot water at times and weak lime water will sweeten the soil.

The drainage must, however, be kept free, and this is sometimes difficult at the end of the season, when the pots are filled with roots. Punching holes through the ball to the drainage will generally relieve water-logged plants.

This chapter is largely writings which have appeared in the American Florist and are from T. D. Hatfield, Wellesley, Mass., who has been eminently successful in this important branch of chrysanthemum culture. 


\section{CHAPTER V.}

\section{MISCELLANEOUS PLANTS.}

Standards.-The cultural directions given for specimen plants will be suitable for this purpose. The greatest difference being the training, allowing them to grow without stoping until they have attained the desired height. Standards are generally about five feet to the lower branches, although there

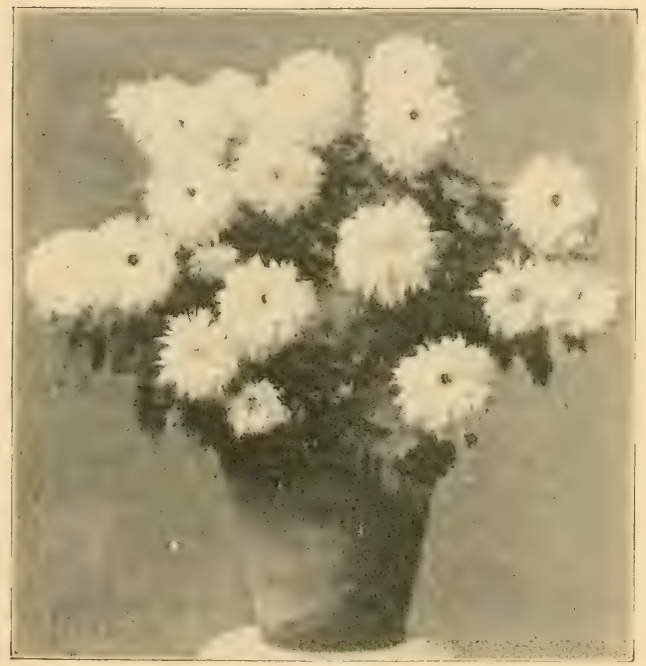

Fig. 4. Market Plant. is no fixed rule on this subject, and they may be grown a $\mathrm{ny}$ lieight, from three feet (which a re termed halfstandards,) to the $\mathrm{height}$ mentioned a bove. It is necessary the cuttings be propagated early. When needed, provide w it h on e strong stake for each plant, to which it is tied to keep the stem as straight as possible. As soon as they, reach the desired height pinch out the center. The several breaks which follow form the foundation for top or head of the standard. These are nipped every few days the same as specimen plants. The training will require same care and attention, as well as disbudding, feeding and other details. 
For Murket.-Dwarf plants of symmetrical form, with foliage down to the pots, are the most salable, and when thus grown require constant attention as to watering and stopping, allowing each plant plenty of room to keep the lower leaves in a healthy condition. Cuttings taken June 1st and grown on, either in pots, planted on old carnation benches, or in spent hot-beds, (light soil preferable) and lifted by August 15th will make very nice plants $1 \frac{1}{2}$ to 2 feet high. The reason for lifting early is to have them well established in their flowering pots before the buds are formed.

Another system is sometimes employed which gives very dwarf symmetrical plants and often utilizes considerable stock that would otherwise he worthless. Cuttings that were struck late in June and potted in two-inch pots may be put several together in one pot about August 1st provided they are in thrifty condition. Three plants to a five-inch pot and five or six to a seven-inch and so on. By sorting and placing the taller in the center and shorter at the edge, very symmetrical plants may be had. Disbudding and feeding will need attention to assure best results.

Single Stemmed.-The same culture as given for market plants will suffice for this class, except they are generally grown in pots and restricted to one stem and flower. Those from one to two feet in height are more effective and useful than taller ones, for this reason many prefer plunging out-ofdoors where they will have full benefit of the sun and air, making them more dwarf than those grown under glass.

Miniature.-There has not been much attention given to this class in this country, although cultural directions are given in many of the old English works.

The best time to take cuttings is from the first to the last of August, according to the earliness of the variety. They are taken at the period when the buds are just beginning to form and if delayed until very far adranced, the wood becomes hardened and do not root freely. These cuttings should be potted immediately into light soil and placed in a close frame which has been made up the same as a hot-bed with 
fresh manure to give forth a gentle bottom heat. After the cuttings have been plunged therein they must be covered with a sash and shaded to keep out the strong light. It is also adrisable to spray them over two or three times a day which will maintain the most genial condition for root formation.

As soon as rooted (which may be ascertained by turning them out) air should be given the frame, a little at first and increasing every few days, to gradually harden the plants to a natural condition. A 3 to $3 \frac{1}{2}$ inch pot is large enough for this purpose. In selecting cuttings take strong shoots from plants in the open border or those grown under glass, and if the selection is made from those which naturally do not grow high, so much the better. In this manner plants can be had 8 inches high with blooms 5 inches in diameter.

For Cut Flowers. - The pot system is employed by all English growers and doubtless most of those on the Continent. Culture, same as for Market or Single Stem as far as training is concerned, shifting from time to time as directed for specimen plants. Propagation may take place from February to May, according to the variety and requirements of the cultivator. Throughout Englanct these plants are potted and plunged in the open border as soon as danger of frost is over, and could be sotreated in this country if it were not for the ravishes of the Tarnished Flant Bug, which is so numerous

If exhibition blooms are desired they may be grown to single stem, or stopped early in June, saving three breaks which are grown on, each to produce a flower later.

rrafted.-There are two objects in grafting chrysanthemums, first, to increase the vitality of weak growing varieties by grafting upon strong kinds. Second, to display a number of varieties on one plant at the same time. To the experienced gardener this art is of little or no interest, but to the novice there is something wonderful in the sight of a plant having a duzen or more distinct varieties flowering simultaneously. such plants attract a great deal of attention at the exhibitions.

Where it is the desire to increase the vitality, cuttings are 
struck in the autumu or winter months, and grown on in a cold greenhouse until early spring. These are used as stock upon which to graft, and should be done in March or April. Select scions from the weak growing kinds and cut the end in the form of a wedge. After cutting out the top of the stock an inch or so above the ground, make a slit an inch in depth in the stump and insert the wedge shaped scion, tying securely in place with raffia or light cotton yarn.

It is necessary that the wood of both stock and scion be in a half-ripened condition, reasonably firm, and if possible have both the same size. In case it is impossible to find scions of the same diameter as the stock, the scion should be set to one side of the incision so that the bark of both will he even on one side. A moist, warm corner of the greenhouse or any place where a close atmosphere can be maintained for a few days will be necessary to insure their uniting. If the weather is warm and the sun very bright it is sometimes advisable to shade the plants to prevent scion from wilting, and occasionally sphagnum moss is wrapped around the union and the foliage moistened to prevent too rapid evaporation. As soon as the scions become established, which is generally in the course of eight or ten days, the tying material can be removed and the plants given more air, receiving the same care and attention as other plants.

For grafted specimens it is important that all the varieties should flower at the same time, and to secure maximum effect some thought should be given to arrangement of the colors. The most showy specimens are produced by grafting upon strong growing standards, using one variety to each shoot. All lateral growths or breaks starting out of the stock should be removed as fast as they appear.

In Open Bonder-Nost of the previous forms of plants may be grown in the open border with fairly good success. The essential points are that they be planted on light soil which permits of their being taken up without breaking away too many roots. If large specimen plants are to be treated this way, ample space must be given so they do not become crowd- 
ed, and afford the operator room to attend to stopping, etc.

The lifting and potting should be done not later than August 15th, so that the plants will become well established in their new quarters before buds are formed. After potting it is necessary they have a copious watering and be set in a sheltered place out of the sun and strong drafts as much as possible. An old shed that will afford some light is a very suitable place.

From this time on little water will be required at the root until they have become thoroughly established. It will be advisable, however, to dew over the foliage several times each day to prevent flagging. As soon as established, give light, gradually increased each day until they can stand full sun.

Hurly Chrysanthemums.--IIost chrysanthemums are hardy out-of-door's in the northern states with slight protection as far as their roots are concerned, but fail to be satisfactory owing to early frosts which ruin the buds when in a half-developed condition. The most serviceable varieties are the early flowering Pompons, which perfect their flowers before frost. Many of the later ones can be used to advantage in the southern states, or in localities where severe frosts are not expected until the middle of November.

\section{CHAPTER VI.}

PACKING PLANTS.

For Express.-For shipments not requiring more than five or six days to reach destination, pack in wooden boxes that have been previously lined with paper or other material to keep out the frost. The plants should be thoroughly watered, turned out of the pots and wrapped tight in some sort of pliable paper to keep the earth intact. With a light coat of excelsior on the bottom of the box, the plants are then placed in rows close to- 
gether on their sides, with ball of earth next to end of the box. This is followed by another row in which the ball is placed next to that in the first row, the operation being repeated until bottom of the box is covered. In putting in the next tier, reverse them, beginning at the other end and so continue until finished. The main object is to pack securely, preventing them from shifting, even though roughly handled. Any intervening spaces between the plants and side or top of the box should be filled with excelsior, sawdust, or some other material, so that if the package is turned upside down they cannot move about.

Inexperienced packers invariably fail in this respect and often when the plants reach destination they have so shifted in the box as to be entirely destitute of soil, as well as badly broken. See to it that they cannot move.

Each variety must he labeled and some means provided so that the recipient ('an unpack without danger of getting them mixed. A system many have adopted is to wrap one, two, three or four plants of a kind into a bundle, each bundle being provided with a label, and are thus packed. Where five or more of a kind are ordered they are separated by a sheet of paper.

In very severe weather it is sometimes necessary to wrap the boxes with several thicknesses of paper as a safeguard against frost. In very warm weather the foregoing method is impractical, as they are likely to heat and thus be ruined. From May to October the plants are generally wrapped and set upright in shallow boxes which have been provided with a post in each corner to which cleats are nailed. Then slats are placed an inch apart to form the cover, thus assuring a free circulation of air.

For Muil.-In packing plants for mail shipments the soil is washed from the roots, these are then wrapped in damp moss and paper in small bundles, containing not to exceed 25 in each bundle. These are generally labeled with a tough paper label and packed in paraffine lined boxes or those 
made of corrogated board. All unoccupied space must be filled firmly with excelsior or similar material.

For Export.-In packing for export there are two systems employed, one for the winter months, when they are packed tight, and the other for summer, which should provide light and air to the plants. When packed close, excessive moisture is to be strongly guarded against. Cnder such conditions the plants are sure to rot if they are to remain packed more than six days. There is sufficient moisture in the plant itself to retain vitality for some time, and whatever is used to fill up the intervening spaces should be perfectly dry. Moss, excelsior or cocoanut fiber are the best materials for filling.

Plants that are to be exported should be put into a cold, airy house for a week or ten days and watered very sparingly so as to harden the wood. If packed too soft, they generally perish. Before placing in the boxes remove most of the foliage as it is very apt to die and cause decay. The balls of earth should he wrapped in dry moss and tied securely. Place the plants in an upright position, on the bottom of the box, using a cleat to each row; in this manner they are held secure in the desired position. If the weather is severe, protection against frost will be necessary, and may be provided as previously described.

In hot weather the same method is employed with the exception that wet moss is used, wrapping each ball with wax paper. Iloles are bored through the sides of the box to admit light and air. The holes are generally covered on the inside of the box with galvanized wire screen to keep mice from girdling them while on ship-board.

Small foreign shipments are sometimes made by removing the soil and placing the plants in tin boxes, filling the intervening spaces with dry cocoanut fiber or moss. It is very important when packed in this manner that all the leaves be removed except those uncleveloped at the top. If the plants have been hardened there will be little loss. It is easy to test a system of packing by preparing shipment, open after a period sufficient for its delivery and note the condition, or if desired pot them to ascertain how many will survive. 


\section{CHAPTER VII.}

\section{EXHIBITION BLOOMS.}

In beginning this section we wish to impress upon the reader the fallacy of laying down hard, fast rules, as most of the best growers obtain their results under a system of their own. The English growers consider it important that cuttings should be taken in January and February, and grown along slowly for best results. Their method of growing is in pots, however, and the one generally employed in this country is the bench system.

The private gardener who has ample space can follow this method with good results, but the commercial grower whose space is so valuable, can scarcely afford to do so and must depend on cuttings struck later. March and April are doubtless the months when the bulk of the cuttings are rooted for this purpose. The note on selection of cuttings for specimen plants will apply in this case.

Assuming the cuttings have been rooted and potted in small pots, they should be kept in a light, airy house to prevent them from becoming drawn and if the planting cammot take place until the first of June they will need to be shifted to three-inch pots, so as not to become pot-bound. Should it be impossible to provide room for this stock after having been repotted, it will be better to put cuttings in the sand May 1st, and plant directly from two-inch pots. In this way the plants will not be hardened in the least and push forward without delay.

Asto soil, this was fully defined under heading of Specimen Plants. It is best not to have it too rich at planting time, but add fertilizers little by little as the plants require it. In this way there is less waste of material and the plants receive the maximum benefit.

Partially decayed sod is an excellent material to which plants take kindly, and if no manure has been added the cultivator has complete control of the varieties under his care. Some varieties, like Mme. Carnot and its sports, are injured by rich soil. By following this plan each variety can be treated according to its requirements, giving one or 
more applications of top-dressing or liquid fertilizers as desired. This work should be deferred until the plants show signs of active growth, which is generally during July.

Planting.-Those who have houses of sufficient height and can plant by May 15th, doubtless have best results in as much as the plant has a longer period of growth and becomes thoroughly established.

As to depth of soil it may be used from four to six inches, the former preferred, as there is less liability of its becoming sour before the plants are well established. When the benches are made ready and filled with soil, the next step is to decide how far apart they shall be planted. There are many opinions upon this subject and without question the best results are obtained where ample room is given for full development of the plant. With most varieties ten inches apart each way is little enough, although a few kinds which produce small foliage might be planted closer. In planting firm them well, leaving a slight depression around each plant to receive the first few applications of water, but do not wet entire until the plants make new roots and are strong enough to utilize all the soil.

It often happens (for various reasons) that it is not practical to purchase new stock to replace those having been pot-bound, and thus hardened. In such cases plant them down to the soft growth or on their side, layer fashion, allowing only the soft top to extend above the soil. As the season advances this layered portion will make roots and assist materially in the construction of the plant. This method is advocated only when absolutely necessary.

Firming.-After the plants begin making rapid growth, go over the bench with a brick or heavy mallet and firm the soil, so that the original four inches will not exceed three when firmed. If of a porous nature it can scarcely be overdone, but if stiff clay, caution is advisable lest the drainage be impaired. By, planting in shallow soil and firming itwell, conditions are established very similar to those of the pot system, which will produce short-jointed plants. 
Tying.-As soon as the plants are 8 inches in height some arrangement must be made for staking and tying. There are several systems:- dwarf, short-jointed varieties, like Merza and others, may be tied to wires running full length of the row, supplying additional wires when required. See Fig. 5.

Some use stakes fastened at the top to a wire stretched tight over each row. Most commercial places use the twine system, which consists of two wires, one over each row of plants and the other a few inches above the soil. Two-ply jute twine is

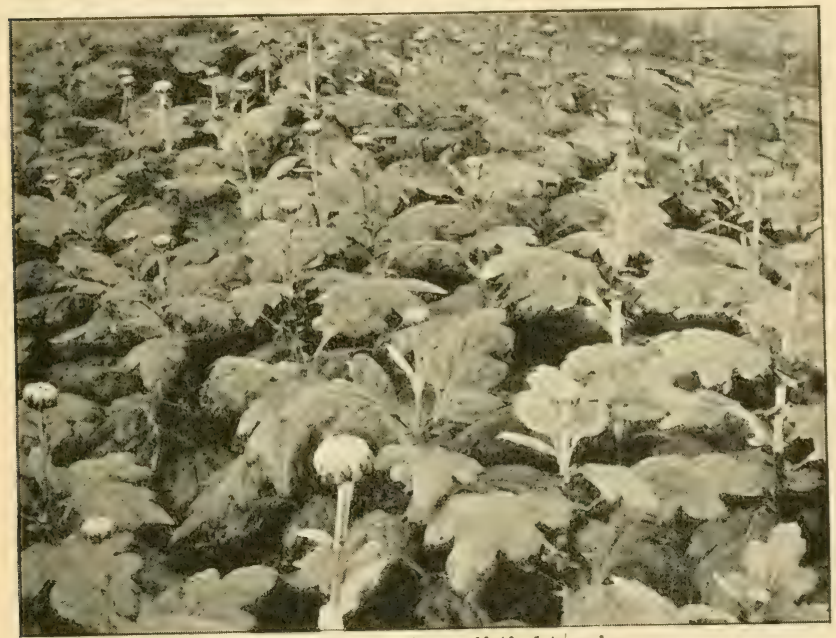

Fig. 5. Bench of "Ivory" tied to wires.

cut the proper length and tied to top and bottom wire. To this twine the plants are tied as often as required. See Fig. 6.

Watering.-From this time on the principal detail is watering, which requires constant attention and discretion. The plants being vigorous will use up cuantities of water each day and at the same time we must guard against overdoing, particularly is this the case with many of the weaker growing sorts which suddenly tell us of their maltreatment by the foliage 
besining to turn yellow, showing a sickly appearance. The best remedy is withholding water, not to a degree that will injure the plant for want of it, but sufficient to regain its normal condition. Let the appearance of the foliage be an index to to the supply of water.

Spraying.-Spraying overhead will be necessary to keep

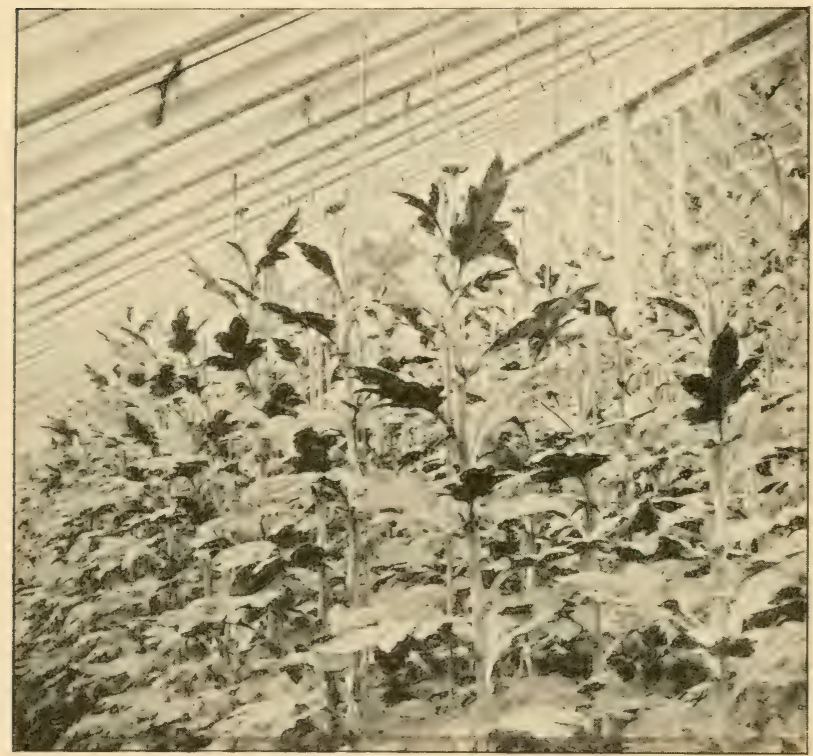

Fig. 6. Bench showing plants tied to twine.

Red Spiders in check, which are very hard to control. This process will require some judgment, for if repeated too often or late in the day it is apt to cause rust and other diseases. There is not so much danger during the hot summer months, but from August 15th to flowering time no water should he applied after $3 \mathrm{p}$. m., so that the plants will be perfectly dry at night. (See diseases page 55.) 
Aiving.-The chrysanthemum does not enjoy a close, stuffy atmosphere, hence an abundance of air during the growing season is important.

Shading.-A few years ago it was considered necessary to give a light shading through the summer months to chrysanthemums planted under glass. This is hardly necessary in most localities, as shorter jointed plants and firmer wood result from full exposure to the sun.

At the approach of color it is quite important the pink and red varieties be partially shaded from the direct rays of the sun, as these colors seem to be easily faded. There may be localities where this would be unnecessary, but in the middle states it often continues warm and bright into Octoler and such precaution is necessary to secure color of the highest degree.

Scalding.-After a few days of dull weather, (which makes the growth unusually soft) followed by very bright sun, the young tips sometimes scald or burn. In such cases use every effort to prevent them from wilting. Frequent spraying will keep the atmosphere charged with moisture and be very beneflcial. Should this fail apply a light shading of clay to the glass. This is prepared by adding sufficient clay to water to make it muddy and applied by spraying over the roof. It is not wise to use a permanent shading and the one suggesteri will be removed by the first shower, or by spraying.

Top Dressing.-In the course of from six to eight weeks after planting, the details given will have been attended to and the stock making rapid growth; the roots having extended to all parts of the soil. At this period they will require some additional food and a light top-dressing of manure from spent hot-beds in a half rooted state, or dry pulverized cow or sheep manure may be used to advantage.

If the stock has been planted by May 15th, this operation will take place early in July, and 30 days later the second topdressing may be applied. If the planting does not occur until the first week of June we would advise giving the first topdressing second or third week of July, and second the 
third week of August, provided the plants are in a healthy, active state and appear to need further encouragement.

While top-dressing is very beneficial, it has one disadvantage, and that is covering the soil so its condition cannot be readily determined by the eye. Some use three inches of topdressing and apply it all at once. Watering under such conditions and do justice to the stock is difficult, as it must be done by guess or the soil under the dressing be carefully examined; it may be dry in places and wet in others. By making the manure fine, adding and thoroughly mixing an equal amount of loam, will furnish material for an excellent dressing. This can be easily distributed on the benches any desired thickness, in accordance with the needs of the variety being treated, or in consistency with the strength of the material used.

If sheep manure is used one-inch of this mixture is ample for the vigorous kinds and less for the weak ones. When horse or cow manure is used $1 \frac{1}{2}$ inches will be about right. This should be firmed down to come in close contact with the soil. In this way the dry spots will be apparent on the surface of the beds, which is the main object of this process. In case the manure is not made fine enough, it may be necessary to cover the dressing with a thin layer of soil so the conditions will be apparent at the surface.

Removing Stools.-Plants that have been top dressed soon throw up stools or suckers from the ground. These should be removed as soon as they appear, care being taken not to injure the roots in so doing. This operation should be repeated from time to time as necessity demands.

Should the plants appear to need stimulants prior to the times for top-dressing it will be safe to give them a very diluted application of liquid fertilizers. If such fertilizers as nitrate of soda, and sulphate of ammonium, or nitrate of potash are used it should not be stronger than $1 \mathrm{oz}$. to $6 \mathrm{gal}$. of water. It is true they would stand a stronger application without apparent injury, but it must be remembered that in a few days the top-dressing is to be applied and when giren a thorough 
watering they receive another dose which is usually much stronger.

IBlimel firmell. - If liquid fertilizers are used often, or strong, the plants will become too gross at this early stage of development. Such treatment sometimes causes some varieties to become blind, that is the joints do not elongate but form a compact mass of foliage at the top of the stem and literally refuse to produce buds.

At the first indication of such a condition it will be wise to discontinue feeding, and if early in the season the plants will make a side-break and produce buds later on, but will not be of much value as an exhibition fluwer. See Fig. 7.

II e do not advocate the use of licpuid fertilizers or overly rich soil in the early stages of growth. Plants that are reared upon solutions wholly, do not make as strong root growth as those grown under more natural conditions.

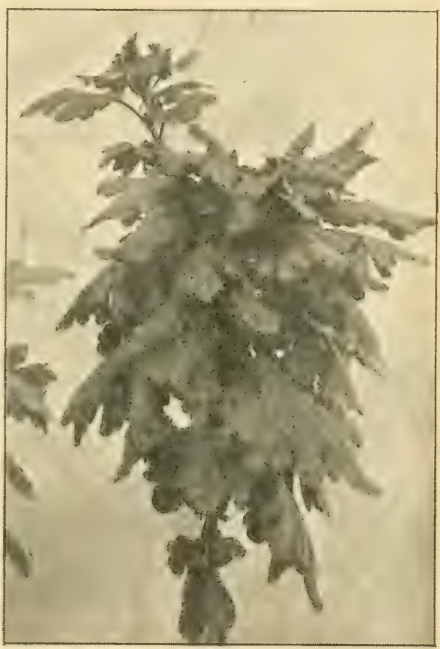

Fig. 7. Overfed plants.

In the first instance there is no reason why the roots should ramble, in as much as the food is constantly provided in the available form of solution. In the other case the roots naturally reach out in every direction for mineral and humus deposits of the soil.

Plants grown more naturally will develope abundance of roots and be in better condition to receive the continual application of stimulants later in the season, at a time when it is ad- 
vantageous to concentrate all energies possible in the development of buds.

Chemical Fertilizer's.-In the use of chemical fertilizers most of the failures are due to too strong applications. Our formula is a highly concentrated compound, consisting of four parts phosphate ammonium and six parts of potassium nitrate (salt petre). This mixture makes a very complete fertilizer.

The formula recommended is perfectly soluable and should be used at the rate of $1 \mathrm{oz}$. to $10 \mathrm{gal}$. of water for a maximum dose. Some will consider this a very weak solution, but experience has shown it sufficient and the old adage "better be safe than sorry" will be appreciated by those who use such concentrated chemicals indiscriminately.

Once a week is as often as it should be applied to most varieties, and never when the plants show signs of dryness, or too soon after dressing: it is better to wait two weeks and note the effects of the top-dressing.

It is a great temptation to those who have not used chemical fertilizers to overdo. It must be taken into consideration when feeding solutions of any form the plant takes them up through its roots, immediately going through the process of asassimilation.

Food applied in this way is more availabe to the plant than any other, and herein lies our great danger; we are applying a solution which is colorless, odorless and tasteless, having every appearance of water.

Lime.-Lime and iron enter into the construction of the plant to a limited degree, but both of these are generally found in sufficient quantities in most soils. Lime acts as a decomposing agent, liberating ammonium and minerals contained in the compost, and has a decided solidifying effect upon the plant tissues. It is best applied by dusting air-slacked lime lightly over the surface of the bed and should be rubbed in with the hands or slightly raked before water is applied, otherwise it becomes bard and is of little value.

Iron.-Iron may be applied in the form of iron filings as a top-dressing or incorporated in the compost, at the rate of a pint 
to the bushel, or by dissolving a half-ounce of sulphate of iron (copperas) in five callons of water and apply this solution. It may be added in small quantities to chemical or manural liquids.

The chrysanthemum, unlike most plants grown under glass, has its season of growth and its season of flowering, hence our object is to produce good, healthy growth and concentrate all energies to the development of the flower. Some varieties will stand much more food than others and profit thereby. To reach the acme with all varieties the grower must be familiar with the special requirements of each, knowing when to stop feeding this variety and increase the applicacation upon another. It is but a step from success to failure, and so it is in these days of close competition, the expert wins out in one class and his opponent defeats him in the next; each having brought their exhibits to the highest degree of perfection in one case, and a trifle faulty in the other.

Feeding is generally continued until the buds begin to burst and show color, and some growers do not discontinue until the flowers are half developed. But if such a course is followed we would advise diluting the application to one-half the strength used when the plants are in an active growing state. We must remember that after buds are formed, the growth, as far as the plant is concerned, is at an end, and whatever we apply in the way of food is immediately taken to those parts which are now being constructed, namely, the petals.

At this stage of development the foliage on healthy plants will be dark green and glossy, which is due to the high living, but is not indicative of excessive feed; unless the leaves are curling badly and very brittle. Under such conditions caution is advisable. The mastery of this important detail can only be gained by the closest observation, learning to know the need by appearance of the growth.

It is no great credit to stage a winning dozen if hundreds have been ruined to secure this "survival of the fittest," it is high average that denotes accomplishment in this art. 
Liquid Mamure-Liquid manure was in use years before chemical fertilizers were known and in the hands of the inexperienced is much safer. There are so many ways of formulating liquid manures that it impossible to give a definite rule with assurance of having the best. Those of experience know by the color when it is safe to use, but such knowledge is difficult to impart to others.

The following rules are considered safe: $1 / 2 \mathrm{bu}$. of horse or cow manure to $1 \mathrm{bbl}$. of water. These proportions are practically $1 \mathrm{pt}$. to the gallon, so that those requiring a small quantity can make to suit their needs. Sheep manure is strong and will require $1 \frac{1}{2}$ bbls. of water for the same quantity. Hen and pigeon manures are excellent, but being very strong are safest when used in weak solution, and should not exceed $1 \mathrm{lb}$, to 10 gallons.

In preparing these liquids the manure is generally put in a coarse burlap bag, allowing it to soak for two or three days. A lox or barrel may be filled and apply water, leach fashion, but the liquid thus obtained is very strong and will need diluting. An old rule is to dilute to the color of weak coffee, but this is hardly safe as some of the strong manures give light colored liquids.

As, we know little regarding the strength of solutions made from material at our disposal, the subject is more or less a matter of guess. Fine blooms may be obtained by their use, and by closely observing growth of the plant and quality of flowers it will soon be apparent how to use for best results.

Burning and Damping.-Experience teaches us that the red varieties are more sensitive and first to show this defect. Some of the pink and white and occasionally a yellow burn or damp when conditions are favorable. From the fact that flowers produced under ordinary cultivation are seldom thus affected it is quite apparent that the concentration of food to the petals is the main cause and this is augmented by excessive heat and moisture.

To avoid such conditions put on full air early in the day and if possible do all the watering at this time, so that the plants and atmosphere may become thoroughly dry before night. 
In very damp weather it is sometimes necessary to put a little heat in the house to keep the air dry and buoyant, even if not demanded by the temperature.

The accumulation of food elements in the petals beyond a certain amount are transformed by chemical action of heat or dampness into an acid, which dissolves the tissues. Why this defect is so apparent in some varieties and not in others we are unable to say, unless lacking in the quality of substance. Get varieties thus inclined into active growth, and discontinue feeding after the buds become half dereloped. They may lack a trifle in size, but be consoled by the fact that your flowers are not ruined. Some competent growers advocate the use of charcoal dust mixed in the soil as a preventive.

Buds and Disbudding. At just what time to save the buds is ever a very perplexing problem to the expert, inasmuch as climatic conditions have a great deal to do with the results. The change of temperature which takes place in the autumn months has a tendency tu ripen or solidify the wood, which is immediately followed by bud formation. In the northern hemisphere this change grenerally takes place from the 1st of August to the 1 st of September, accorling to location. Those living at a high altitude or adjacent to large bodies of water are first to feel the change, hence favored with early buds. In the southern hemisphere this change takes place during February, and for this reason the chrysanthemum flowers in Australia during the months of March and April.

II aving set forth these facts that climatic conditions are instrumental in bringing about this desired bud state, we must all consider our own locality and be governed accordingly. Some of our best experts secure buds on some varieties as early as the tenth of August; and get magnificent blooms therefrom. Doubtless they have solved the problem, as far as they are concerned, but there are others not so favored. We doubt if those located in the middle states where the heat continues through the month of August and sometimes into September, would 
find such an early date practical, unless for some of the early varieties which naturally set early buds.

In this locality (Southern Michigan) best results are from buds taken August 25th, or soon after. As soon as the new varieties are brought under our care we make a record of

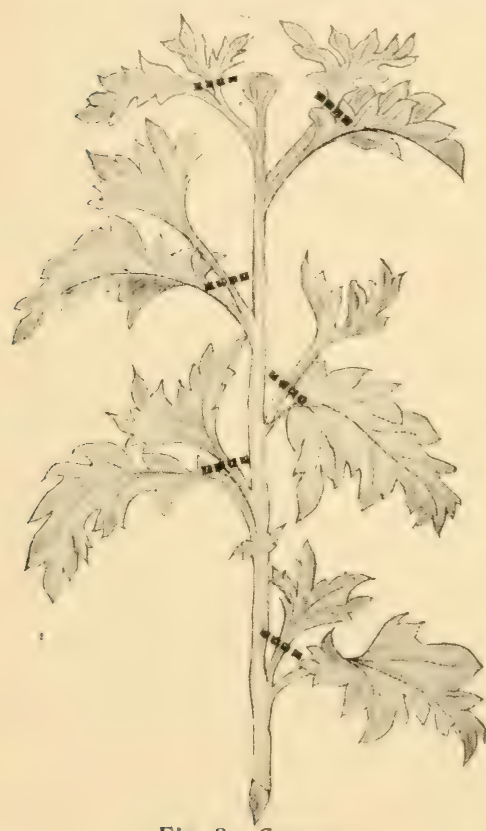

Fig. 8. Crown.

the date of disbudding, selecting a few of the earliest, and repeating this operation as far as possible every tive days, up to the middle of September. When the flowers are cut we make a record of best dates, and the next year we are in fair position to know just what course to follow. These records are made on tree labels and attached to the plant.

Taking the Buds.Taking the buds is an old and obscure term whïch simply means selecting the best and removing all others. There are two forms of buds, Crown and Terminal. The Crewn is formed flrst and if removed the lateral growths which surromul it will make buds later. The Terminal bud is the termination of the final growth and must be retained as there are no buds to follow. They have also been termed as follows: A Crown bud is surrounded by vegetative shoots and not by other buds. A Terminal bud is surrounded by other buds and not by vegetative shoots.

()n plants that have been planted early the crown buds often 
become apparent early in August. See Fig. 8. If these are removed the adjacent vegetative growths push forward and will set another bud which is generally a crown and often termed "second crown," late in August or 1st of September; much depending upon climatic coulitions and tratment of the plant. If this bud is removed the lateral growths will push forward, and in the course of a few weeks develop a cluster of buds which are terminal or final, as this completes the plants growth. See Fig. 9.

The chief merits of the crown bud are earliness, size, and multiplication of petals. Many of the foreign varieties, particularly those raised in $\mathrm{England}$, a re worthless from late buds, producing flowers with open centers, and in many cases so much so that they could be classified as single. The tendency

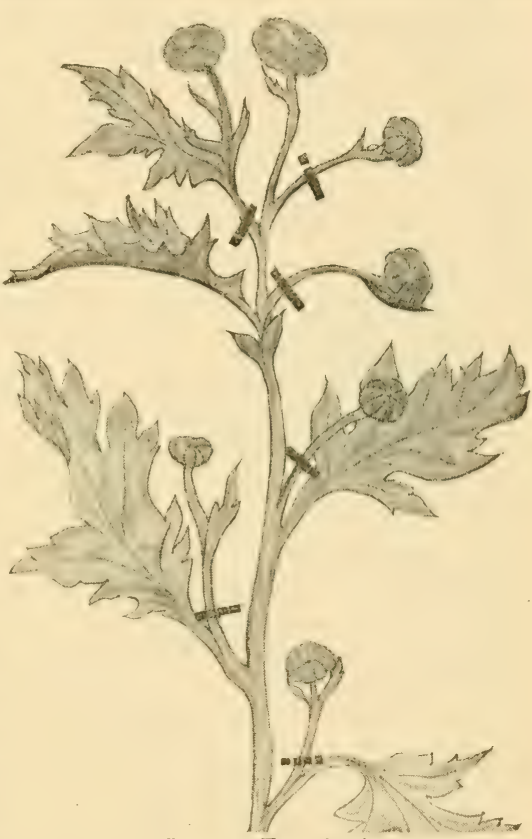

Fig. 9. Terminal. of crown buds is towards loss in substance, color and foliage. Varieties that produce pink or red flowers from terminal buds are inclined to be white or bronze from crowns.

The lack of foliage is due to stems of crown buds continuing their growth until the buds have reached full size. This peculiarity is more pronounced in the tall growing varieties or 
those which make long growth between the leaves and are commonly called "long jointed." See Fig. 10.

It has been suggested that the term "single bud" be applied to the one known as crown and "cluster bud" to the one known as terminal. We can see no objection to using these terms and thus may be able to convey our ideas to the amateur more clearly.

If we decide to save the crown (or single bud,) remove all lateral growths, as shown by the dotted lines in Fig. 8, and the operation is complete. Then terminal (cluster bud) is desired,

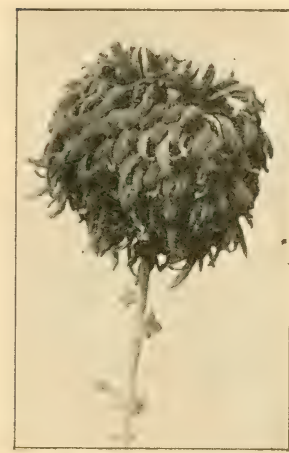

Fig. 10. Bloom from Crown. remove the crown, allowing one of the lateral growths which surround it to remain. In the course of a few weeks this growth will have attained some length and show a cluster of buds. When well advanced it will be noticed that there is one at the apex of the stem and one at each of the leaf axils, as shown in Fig. 9.

If the center or apex bud appears perfect, retain it by removing all others with the thumb and finger. This operation is termed "disbudding" and should be done as soon as buds are of sufficient size to do the work without injuring the one retained. Should the center one be imperfect or injured from any cause, save the next best.

The whole subject of buds resolves itself into a few simple facts which each grower must take into consideration before taking any decisive steps; viz.: climatic conditions, date of the exhibition, classes in which they are to compete, and peculiarities of the varieties under consideration.

The operation of disbudding should be confined to the early hours of the day as far as possible, at which time the growth is more brittle and can be easily removed with thumb and finger. As soon as the buds are formed lateral growths 
from the leaf axils push forward. These should be remored as fast as they appear, or the bud will be robbed of nourishment which has been previously provided.

Stopping-- Nost of the exhibition growers of England give considerable thought to what they term "timing" the buds, that is, have the flowers in perfection at a certain date. To this end they resort to stopping many varieties. The object is to force flowers at an earlier date than they would naturally mature if allowed to make a natural break. This system has not been practiced in this country to any extent, although it may be worthy of consideration as competition grows keener.

Record of Operations.-In a work where there are so many conditions which have influence upon the result, it is very important that each operator keep a fairly complete record of quantity and quality of fertilizers when applied, height of plants at maturity, date of bud, and general comments as to merit. Such records are invaluable for future reference.

\section{CHAPTER VIII.}

EXHIBITION BLOOMS.

Grown Out-of-doors.-It is not to be presumed that success can be achieved in exhibition blooms grown out-of-doors, where very cold weather creeps into the lap of Autumn, or severe frosts and freezing weather may be expected during the month of November, therefore, it should be hardly attempted in other than the southern states. The best location in the garden for this purpose should be one protected as much as possible from storms, blowing rains and wind, and all the better if a spot 30 to 40 feet square can be selected, and a 6 -foot close board fence built all around.

It is a mistake to set out plants for this purpose earlier than May, and eren as late as. June, although many growers are in the habit of commencing earlier. The results they have at blooming time are great tall plants, inclined to be spindling and not of that sturdy, stocky nature which invariably produces 
the better blooms. Besides they have worked a month or more at their plants that is wholly unnecessary.

Soil should be of a rather stiff than loamy character, liberally fertilized with manure from the cow lot, which will make it sufficiently rich and porous for a beginning. Beds should be parallel, three feet wide, with two-foot walks between and raised six incbes, that drainage may be had at all times. It is well to box in the beds with boards six inches wide, and use a few inches of gravel for the walks between the beds. Two rows of plants 12 inches apart in the rows are proper distances for setting out in the beds. Get them straight and uniform, and have a few surplus plants in case any should die or fail to start off properly, that the rank and file may be in no instance broken.

Do not use too many varieties, and have at least a row of each kind, selecting those in preference that have been prize takers at the principal flower shows. A plant will make three exhibition blooms of as good quality if well fertilized as it will one; so after pinching off the end when the plant is 12 inches high, allow but three well selected limbs to gruw, and no more during the entire life of the plant, with the object of one bloom to the limb, or three to each plant. The best means of staking and tying is the wire fence method. Place stout stakes as tall as the plants will grow, eight or ten feet apart in the row, stretch wire, fence-fashion, to which the plants are tied and repeat this operation as often as required.

Never allow the beds to become dry, but water and spray the plants each day after sundown, and during August sprinkle with bone-meal around the roots of the plants and give a two-inch top-dressing of well rotted manure from the cow lot. The idea should be to cause the roots to grow laterally rather than downward, hence a great depth in the beds in unnecessary.

Liquid fertilizers made about the strength of weak tea from hen, sheep and cow manure is best, and will contain all the chemical ingredients that the plants will require. This liquid 
fertilizing should commence about September 1 st, and 10 days later the first setting of flowering buds will appear.

When buds show color stop all fertilizing and give soft water. A covering of canvas laid on sloping rafters should be given the beds to protect the opening blooms from rain or dust, in fact not a drop of water should be allowed to come in contact with a bloom at any time, and great care should be used in spraying.

Disbudding will have to be close attended to, allowing but one (the most promising) to each limb, and usually the terminal bud is chosen for best results. The crown or early center bud is best for some varieties, but experience will have to be the teacher. Watch for insects closely: caterpillars, aphis, mealy bugs and corythuca that huddle on the under side of the leaves. Keep on the lookout for these enemies, and at the first indication apply tobacco tea, or strong soapsuds to prevent their getting a strong foothold.

Do not expect blooms grown out-of-doors to be quite as nice as those with greenhouse protection, where the elements can be more surely controlled. The grower should never attempt exhibition blooms of any character if he is not prepared to devote time each day to them, and under no circumstances allow the slightest procrastination or neglect. The plants in time will repay most handsomely.

S. J. Mitchell, Houston, Texas, who has devoted much time and study to the chrysanthemum, particularly the subject of exhibiting and judging, has kindly supplied the foregoing article.

Australian Method. - The conditions in the southern states are similar to those of Australia, admitting of the flowering of chrysanthemums out-of-doors. Thinking that the methods employed there may be of service to southern growers we give the following suggestions by G. Brunning d Sons, Australia. It should be taken into consideration that their spring is our fall; so that where the month is specified we should add six months. This would make September, March, or the proper time to begin propagation. And again, where it refers to the buds appearing in February, we should substitute August. 
Propragution.-- "Stand the old plants of the previous season in some open, airy position to break. From these suitable cuttings of about three inches in length are taken in September (March). After removal of some of the lower leaves the cuttings are inserted singly in two or three-inch pots filled with light, open soil and plunged in sand in a close glass frame. The only attention required until they are rooted being an occasional watering or sprinkling and ventilation for an hour or two in the morning."

Potting and Subsequent Treatment.-"When the plants are fairly established and hardened off, repot into 5-inch pots, using a good open soil and well drained pots. The soil need not be too rich, as only a moderate growth is desirable at the present stage. Pinch out the leading shoot at this time, thus causing the side buds to break and furnish the necessary leading growth. The plants are plunged in sand in an open sumy position and progress rapidly, so that by the second week in November (May) they are ready for 7 -inch pots, when a little richer soil than previously used can be substituted, in which they may remain until the first week in January (July).

Now, instead of removing them into larger pots, break a good sized hole in the bottom of the pot in which they now are and plunge to the rim in a well drained and sheltered bed, placing some good prepared soil under them, (such as a mixture of heavy loam, peat, sand and manure) say in the following proportions: 1/4 heavy loam, 1/4 peat, 1/4 sand, and 1/4 horse droppings; adding some crushed bones, wood ashes, and a little soot. Should heavy loam not be procurable clay may be used as a substitute.

By this method an opportunity is afforded them with liquid manure much easier and oftener than could be done if planted out in the open ground, and the plants will not attain such a height, provided they are firmly potted when shifted into the 7-inch pots.

The only liquid manure we would adrocate is made by filling a small bag with about 28 lbs. of fresh cow dung, adding a little soot (about 4-inch pot full), placing same in a tub contain- 
ing 20 gallons of water, leaving it to stand three or four days before using. Dilute $1 / 2$ pint of this mixture to 2 gallons of water. Renew this preparation every two or three weeks. This manure may be given from the second week in January (July), not oftener than once a week till the buds are taken, as over manuring has a tendency toward promoting blind buds and in their later stages causing blooms to damp."

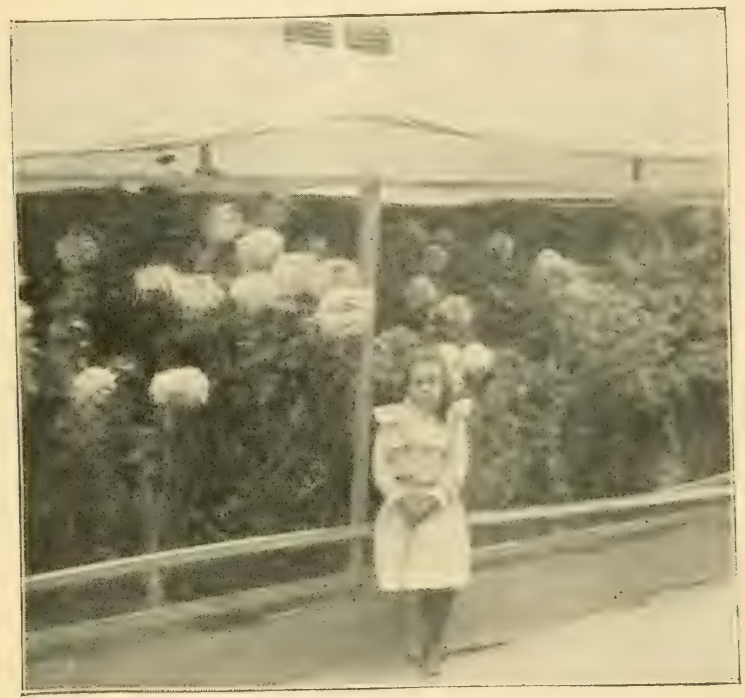

Fig. 11. Shelter or Snug Harbor.

Shelter or Snug Harbor.-At the approach of cool nights protection will be necessary where the flowers are to be perfected out-of-doors. The plan generally adopted is to build a light framework upon which cloth is stretched and fastened to form a roof. For the sides a cloth curtain should be provided and fastened in such a manner that it may be rolled up from the bottom to admit air on pleasant clays. If the plants are 
situated next to a building or tight board fence this will answer for one side of the enclosure to which the framework may be attached. See Fig. 11.

\section{CHAPTER IX.}

COMMERCIAL FLOWERS.

In a general way this subject is quite similar to the preceeding one. As the flowers are raised for the sole purpose of placing upon the market from a remunerative standpoint, the commercial grower has many things to consider in bringing about this desired end. The length of time to produce the

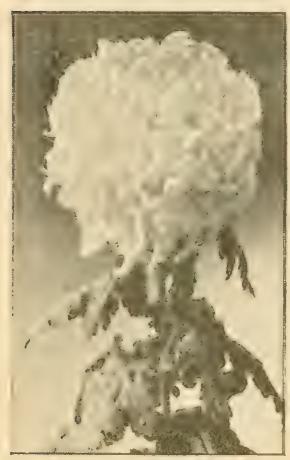

Fig. 12. Bloom from Terminal. crop, and sacrificing other stock to make ready for planting are important factors, and thus the planting is often deferred to a time more opportune. Under these conditions the bulk of planting generally occurs from June 15 th to the latter part of July.

The general details as given for planting, top-dressing, staking and tying, will be practical in this case. If planted late they may be set closer together, and if the demand is for medium rather than large flowers they may be stopped and several breaks allowed to flower. A plan adopted by some is to pot and plant two cuttings together and grow unstopped, each producing one bloom. This is very practical for dwarf varieties and also those having small foliage, of which Ivory is a good example.

Feeding.-Liquid manures, chemicals, or both may be used. The tirst mentioned requires more labor to prepare than chemicals, which if used in large quantities, are the cheapest. Five dullars worth of concentrated chemicals will be ample for 
10,000 plants and sufficient manure could not be purchased and prepared for several times this amount.

Buds.- In this branch of chrysanthemum culture there is little necessity that any great knowledge be acquired regarding the two forms of buds, crown and terminals.

The flower buying public insist that the stems be of good length and well clothed with foliage. All concede those produced from terminal buds are of brighter color and amply provided for as far as foliage is concerned. See Fig. 12.

The bulk of chrysanthemums planted for commercial use do not set early crowns, owing to late planting. Some make second crowns late in August, and those planted in July give terminals in September aud October.

Early.-If the desire is to produce early Howers we cannot too strongly impress the necessity of planting early, and it should be the endeavor to have them benched early in June at the latest. It is foolish to expect early flowers from late planted stock, even though the varieties are naturally early.

Thuse who grow such varieties as Opah, Marcy. de Montmart and the two Fitzwigram's, may take the first bud that appears after August 15th, with the expectation of groud results and have the crop all marketed early in October.

Late.-For later flowers select varieties which naturally mature late, and keep them in a growing state as long as possible. To secure late buds give a liberal amount of water and at the approach of cold nights lessen the supply of air, this will tend to keep the growth suft. The mid season varieties planted late in .July or early August are usually satisfactory. When this plan is adopted do not use very rich soil and withhold liyuid fertilizers until disbudded, otherwise they are apt to come blind. See blind growth, page 35 . Buds secured from ()ctoluer 1 st to 15 th will perfect flowers between Thanksgiving and Christmas.

Ileight of Plunts.--It is sometimes advantageous to take crown buds rather than terminals, owing to limited space between bench and glass. Fig. 13, shows Yellow Mrs. J. Jones, 
the first plant 42 inches high with terminal bud, the other 28 inches high and crown bud. The first made a 14 -inch growth after the crown was removed before setting terminals thirty days later.

To know the height a variety will attain at maturity is important, particularly when head room is limited. If records have not been kept it is wise to confer with those who give these

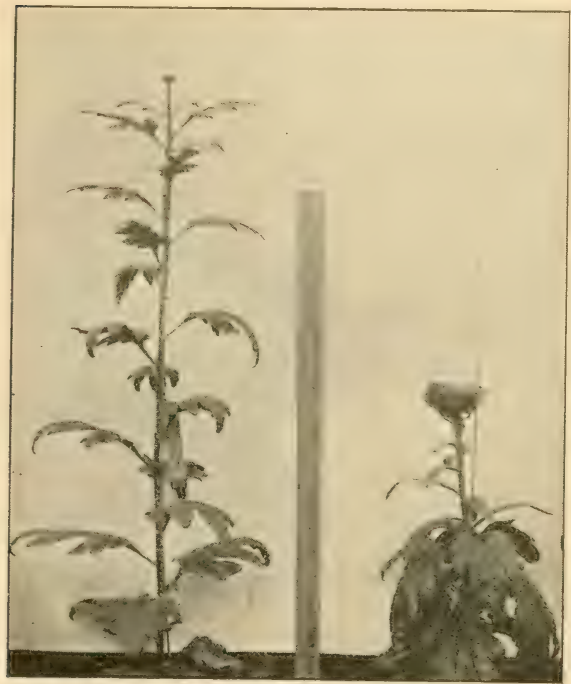

Fig. 13. Comparative Height from Crown and Terminal.

matters constant study and can suggest varieties suitable for the purpose.

When to Cut. -At what stage of development the flowers should be cut is perplexing to some. The petals have more substance when fully matured, and for this reas. on most varieties should not be cut before center petals are developed. This gives greater depth, adding to finish of blooms, as well as increasing the keeping qualities and are thereby in better condition to stand the wear and tear of shipping and handling. It is allowable to cut early varieties unmatured, if fancy prices result therefrom, otherwise it is best to let them stand. Varieties having open centers when fully developed may also be cut premature. All blooms should be stored in water at least 12 hours before sending to the market. 


\section{CHAPTER X.}

\section{INSECTS.}

Aphis.-The black and green aphis infest chrysanthemums in all stages of their development and are very persistent in their depridations. The best remedy is to fumigate with tobaceo stems and manufactured products, such as aphis punk and tobacco dust. If tobacco stems are used it is necessary to dampen them a few hours ahead so they will burn slow and prevent them from blazing, which generates heat and gas that often burns the foliage. The manufactured articles are generally accompanied by full instructions for their use.

It is impossible to fumigate plants out-of-doors and not always convenient to do so under glass. Under such conditions tobacco dust may be applied to the parts infested after they have been sprayed so it will adhere. Such applications are easily removed by spraying, but if possible should remain two or three days before removal. Sometimes tobacco dust is not at hand and the presence of aphis demands prompt action. A decoction made by leaching tobacco stems or placing them in a vessel and covering with hot water for a few hours will have the desired effect, and is best applied by some form of a spray pump. There are several forms of tobacco extracts that may be used in the same way, all of which are provided with complete directions.

Red Spider:-The most difficult insect we bave to contend with under glass is the red spider, which is very minute, scarcely discernible by the naked eye, but if allowed to gro unchecked will become very numerous, forming a fine web about the leaves and buls. It is generally first detected on the undersicle of the leaves where they are not dislodged by spraying. Dry, hot air is most congenial to their welfare and after these conditions have been brought about by turning on heat, houses have been ruined which were apparently clean and gave great promise early in the season.

The best remed! hnown is water, which should be applied in the form of sjoray with as much force as possible to destroy 
the web and dislodge them. It is important that it be applied to the under as well as the upper side of the foliage. Thorough and repeated applications are the only source of relief. Tobacco smoke has little or no effect as far as can be ascertained.

Thrips also infest the chrysanthemum occasionally and thrive under the same conditions as red spiders, although not so much dreaded. Where the hose is used freely and plants well sprayed they are easily exterminated.

Mealy Bug.-As commonly known it is a white, mealy, downy looking insect. Generally it does not infest chrysanthemums to any extent, but we have seen cases where they

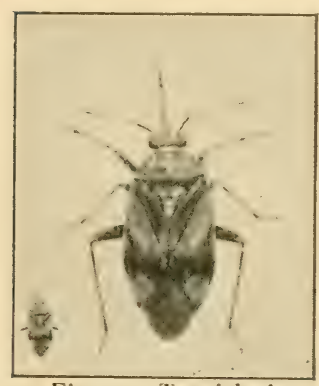

Fig. 14. Tarnished Plant Bug. were more or less troublesome. If not very numerous they may be hand picked. When this is impractical, alcohol diluted one-half and applied with a brush or atomizer will destroy them without injuring the foliage.

Grasshopper's are sometimes troublesome and the best remedy is handpicking. This should be done as early in the morning as convenient, when they are more docile and easily caught.

Tarnished Plant Bug is a great hinderance and often causes total failure to plants grown in the open border. See Fig. 14. They are brought into the greenhouse on various plants, like carnations and geraniums, aud immediately find a favorable feeding ground upon the chrysanthemum. This destructive bug procures its food by thrusting its probuscis into the tender growths, extracting the sap, thus causing the tips to flag which may be considered evidence of their presence. In the young state they are of a yellowish green color and seem to confine their depridation to the apex of the stem and soon destroy the center.

As soon as the lateral growths push forward they take to 
these, and thus the operation is repeated until the plant often becomes a mass of blind growth. 'See Fig. 15 .

The adults are yellowish brown, about $3-16$ of an inch in length, and will continue their destructive work upon any part of the plant or flower that is soft and abundant with sap. They puncture with such violence as to distort the growth and ruin promising buds, and later on deface the petals of expanding flowers. The pest is known in nearly all parts of the United

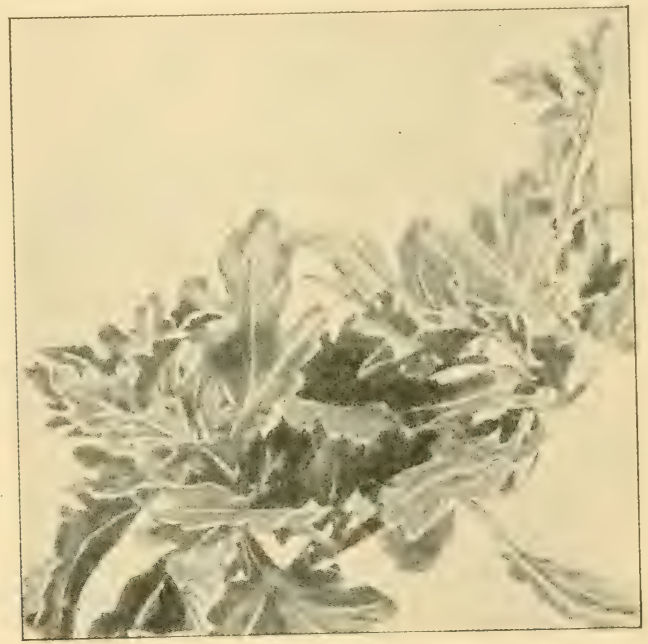

Fig. 15. Depridations of the Tarnished Plant Bug. Branch showing mass of blind growth.

States, being more or less destructive to many other plants, such as asters, goldenrod and sunflowers, and they are very partial to carnation blooms.

Hand-picking is the best remedy we have found, and whoever attempts to catch any of these little intruders must be alert indeed. The alults will tly at the first intimation of your presence and the young either hide under the leaves or drop to the lower part of the plant. 
Corythuca Gossypi is about the size of a full grown aphis, color, a dirty gray, having a woolly appearance. It is more or less troublesome throughout the southern states, but is little known in the north, although it has been reported in many localities. Its habit is similar to the red spider feeding upon the under side of the foliage. It is reported as being very destructive, and the affected leaves curl and die. When disturbed they fly to the ground and immediately return to the plants by climbing up the stems and are soon re-established. The best remedy is weak kerosene emulsion, and this should be applied to the under side of the leaves to be most effective.

Grub Worm.-The common white grub so prevalent in meadows is often carted into the house with the soil. The first indication of their presence is, the plant will begin to wilt and eventually die. They harbor in the soil and feed upon the roots and should be hunted out and killed.

Cut Worm.-This dark colored worm which sometimes attains two inches in length, burrows in the ground and at night feeds upon the foliage of the plant, generally going to the tender leaves at the top. Owing to their nocternal habits they are easier caught at night.

Lady Bird (Coccinella.) - This little beetle varies in size and color, being from $1 / 4$ to $3 / 8$ of an inch in length in the adult form and nearly round. Commonly red with black spots, varying in size and number, and may be black with red spots, or unspotted red or black, also more or less marked with yellow.

In the larva state they are $1 / 2$ inch long, color, bluishgray, more or less marked with yellow and black spots. At a certain stage of development they fasten themselves to the under side of the leaves and in a day or so shed their larva coat and are thus transformed to the winged or mature state. In all stages they feed upon the aphis but are more active and greedy when young. They are also known in this country as lady bug and should never be molested, as their persistent hostility to the aphis is very beneficial.

Goldeneye, also known as lace-wing and lice-lion, is another 
friendly insect feeding upon the aphis. In the ronng state they cover themselves with the skins of their victims. The larvæ is quite similar to that of the lady bird. In the mature form they somewhat resemble the katydid but have no hoppers. The wings are large in propurtion to the body, thin and transparent, marked with a net-work of fine dark lines. When full grown they are an inch or more in length.

Chrysanthemum Fly.-This insect closely resembles our honey-bee, although a tritle larger. When on the wing it makes a similar humming sound but can be haudled with impunity as it cannot sting. It makes its appearance with the first chrysanthemum flowers and disappears at the close of the flowering season.

It cannot be considered a foe or friend, its sole object being to gather bes-breal from the more single flowers. It has been used for the purpose of raising seexl, being an excellent agent in fertilizing flowers as it continually roams from one flower to another. Seel thus obtained camnot be considered very valuable, inasmuch as they never visit Howers that are fully double and the results thus obtained would be degenerative rather than progressive.

\section{CHAPTER XI.}

DISEASES.

Rust is not so prevalent in this country as in England from the fact our atmosphere is dryer. It makes itself apparent with the approach of cool nights and is generally augmented by excessive moisture.

H. J. Jones, Lewisham, England, describes this fungus in the following (omprehensive manner. "It appears the fungus originates in the tissue of the leaf, and is mostly confined to the under side, although there are many instances in which pustules appear on the upper surface of the leaf. A pustule, simply described is a little pimple which bursts, exposing a dark brown dust, at maturity. This brown dust is none other 
than liberated spores which drop out of the pustule, and fall on, or come into contact with the chrysanthemum foliage, and when this is in a moist condition it quickly grows and very speedily developes a germ tube which very soon finds its. way into the tissue of the leaf, and after a time repeats itself."

"There are many remedies given, such as bordeaux mixture, and ammonical solution, as well as other prepared compounds. These, doubtless, are more or less affective, but we can hardly expect a permanent cure from their use unless we maintain conditions that are unfavorable to the development of new spores."

A few years ago the carnation rust which grows and reproduces itself in the same manner, and as far as we know is identical, caused great anxiety among carnationists, who feared its prevalence would gain such a fonthold as to be ruinous. Experience has taught them to remove the cause or conditions under which it develops rapidly. To this end they house the plants early, spray only on bright mornings and maintain a dry and buoyant atmosphere as far as possible.

If chrysanthemum growers will take the same precautions there is little fear of the disease becoming wide-spread, or doing great damage. (Over-crowding the plants so that the foliage does not dry off yuickly, indiscriminate spraying, particularly when applied late in the day in the autumn months, and lack of air should be strongly guarded against.

In aggravated cases it would be well to try the following remedy, given by $\mathbf{W}$. Wells, Redhill, England, in his new work just issued, "The Culture of the Chrysanthemnm."

"Spray every cutting or plant once a fortnight-from the day the cuttings are inserted or the old plants are cut down with about a wineglass full of parrafine (kerosine) mixed with one gallon of water, using an Abol syringe with the spray nozzle. If the solution can be kept thoroughly mixed double the strength may be employed. Then from July 1st spray the under part of the foliage with a dressing compost of the following ingredients: half-pound each of sulphur, soft soap, soot, and 
lime. The lot should be boiled for half an hour in one gallon of water: a half-pint of paraffine should then be added and the mixture allowed to simmer for a minute or so, care being taken to prevent it from boiling over. The dressing should be allowed to stand until it gets clear, and may be kept in bottles. A quarter of a pint of the dressing may be useel to a gallon of water. If, however, the fungus is very bar and has obtained a hold on the plant, double the strength can be used without injuring the chrysanthemum."

Leuf syot.-With this fungus (Septoria Chrysanthemi E and D) the spore bearing cavities are imbedded in the leaf tissue, and as they mature the spores oo\% out of these cavities and thus spread the disease. They may be killed by fumicides applied to the surface of the leaf. Another fungus disease which often attacks the chrysanthemum is known as

Chrysanthemi. It is a more rapid grower than the Septoria and the plants effected by it are often so stricken down as to be unable to make any blooms.

The leaves of the effected plants begin to roll up, the outer edges turning under and this condition becomes so apparent that even the inexperienced grower will know at a glance that something is wrong. Some varieties seem to be strong enough to withstand this fungus, hence in nearly every case where the writer bas known its presence it has confined itself to certain varieties and very often those growing adjacent were not affected in the least.

The best remedies are bordeaux and ammonium mixtures.

The foregoing is an abridged article on leaf spot by Prof. Byron. D. Halstead appearing in American Chrysanthemum Annual.

Bordeaux Mixture.

Copper sulphate...............6 pounds

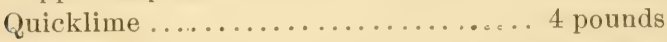

Water ........................ 40 gallons

Dissolve the copper sulphate by putting it in a bag of course cloth and hanging this in a vessel holding at least four gallons, so that it is just covered by the water. Use an earthern or 
wooden vessel. Slake the lime in an equal amount of water. Then mix the two and add enough water to make 40 gallons. It is then ready for immediate use.

Ammoniacal Copper Carbonate.

Copper carbonate..................

Ammonia......... enough to dissolve the copper.

Water........................ gallons.

The copper carbonate is best dissolved in large bottles where it will keep indefinitely, and it should be diluted with water as required.

Mildew.-A common name applied to several forms of microscopia fungi. The one affecting the chrysanthemum is white and forms a coat over the leaves and tender shoots and is caused by a sudden check of some nature.

Sulphur in some form is the accepted remedy, being applied as dust directly to the leaves, or by mixing equal parts of sulphur and air slacked lime, adding water until the consistency of paste and painting the steam pipes. The formula given by $\mathrm{W}$. Wells for rust is recommended for mildew and doubtless is affective.

\section{CHAPTER XII. \\ SEEDLINGS AND SPORTS.}

Before entering the details of this subject let us consider some of the natural conditions which have more or less influence upon our results. Dame nature says the chrysanthemum shall be single and reproduce itself from seed, so in producing these marvelous flowers with almost countless petals we are working in direct opposition to her laws.

In some of our improved varieties we are prevented from making further improvements owing to the pistils or styles being abortive; and in others the staminate florets provide little or no pollen.

In cross-fertilization the operator's desire is to improve the chief characteristics, such as color, size, form and fullness. It 
is beyond all human power to obtain exact results in uniting or mixing the colors of petals. Pollen of a white flower applied to a red may give red, white, or any intermerliate sharles which would be the many varieties of pink. The union of red and yellow give similar results, producing resl, yellow, and all the intermediate shades of brown and tan. We have more assurance when varieties of the same colors are crossed. Improvements in color can only be attained by bearing in mind the laws of nature in making these unions.

The chrysanthemum has a great tendency to revert to its antecedents. Hence it is we get many strangers when two of the same color are crossed. The variety, Mrs. J. J. Glessuer, yellow, came from Edward Hatch and Mrs. J. Jones, both white or nearly so. This seedling partook of the parentage of Ed. Hatch which was Gloriosum, yellow, and Ada Spaulding, pink.

Form, size and fullness are improved only by careful consideration of these fualifications in varieties at our disposal. We are more certain of advancement in the style of growth, securing those which are dwarf and sturdy by confining our operations to such as possess these qualities.

Large and small foliage can be produced by using those having these peculiarities.

What governs the potency of the pistillate and stmminate parent we cannot determine. We are dealing with minute affairs. The stigma may scarcely have reached maturity when the pollen is applied, or the pollen may be passed its prime with the stigma at the height of levelopment. These varied conditions may have their influence upon establishing the character of the seedling.

In selecting varieties for this work the two classes for consideration are those for exhibition and commercial use. In the former, size is the most important fartor if the other yualitications are up to the average. The commercial grower requires staple colors, and the purer the color the better. Size, form, fullness and style of growth are important and should be taken into consi leration. 
Secd Plants.-Our experience leads us to believe that single stem plants in 4 -inch pots grown naturally without an abund-

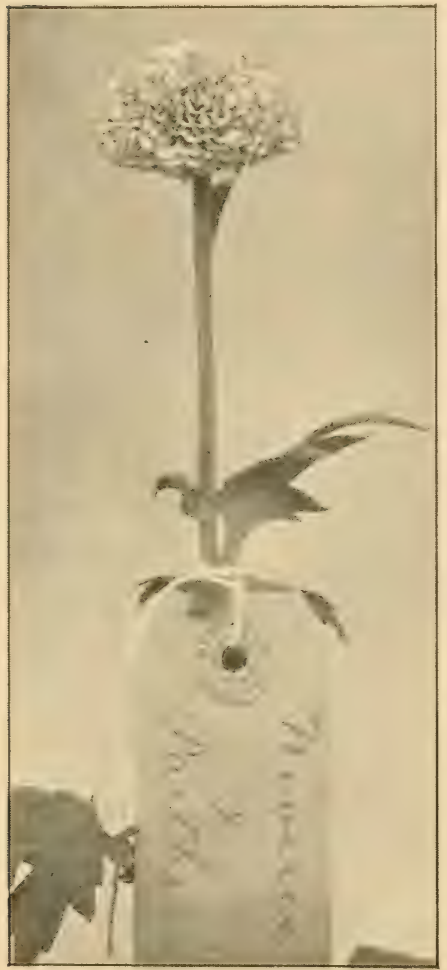

Fig. 16. Flower trimmed ready for fertilization. ance of nourishmentare best suited for this purpose. They produce less ray florets, hence pollen is easier to gather. The styles in flowers thus treated seem to be in better condition, or at least more normal and produce seed more freely. We have arrived at these deductions by endeavoring to procure seed from those grown for exhibitions and in nearly every case our efforts have been fruitless.

Plants intended for seed raising should be staged in a dry, light house, and excessive moisture at the roots or in the atmosphere should be avoided.

Fertilizing.-The operation begins when the flowers are half open by cutting the petals off close to the base with a pair of scissors, until the styles are exposed. See Fig. 16.

Fig. 17 represents an enlarged ray and disc florets. No. I. is a petal which furnishes the color. This is provided with a style or pistil and when in condition or fully expanded is in proper condition to receive the pollen which is applied to the upper surface, (B) known as the stigma. The disc floret 
(II.) also has a style, but is provided with stamens, (C) which furnish the pollen. These should be removed from the seed plant with the points of the scissors to prevent self-fertilization.

After the flower head has been trimmed select the desired flower for pollen. Push aside the ray florets or petals until the disc florets are in view. Collect the dust-like pollen on a camel's hair pencil or toothpick and apply to the stigmas of the flowers previously prepared. This completes the operation.

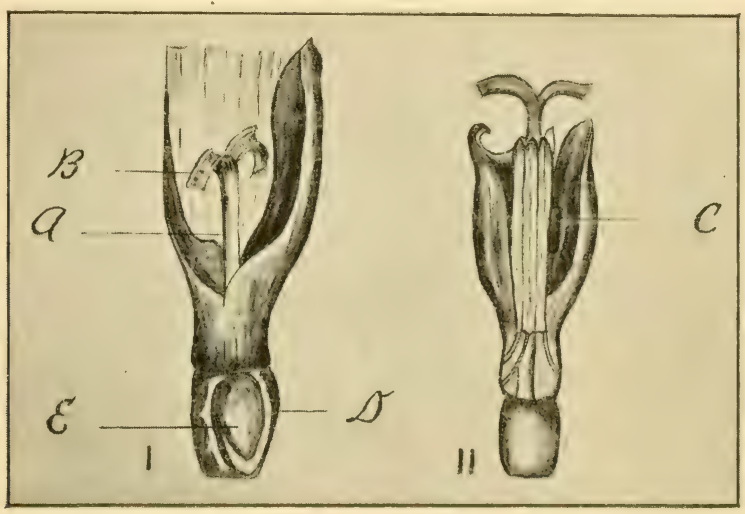

Fig. 17. I. Pistillate Floret. II. Staminate Floret. (A) Style-(B) Stigma. (C) Stamens-(D) Ovary-(E) Seed.

How fertilization takes place is fully described by Prof. Bentley in his Manual of Botany:

"When the pollen falls upon the stigma its intine protrudes through one or more pores of the extine in the form of a delicate tube which penetrates through the cells of the stigma, by the vivid secretions of which it is nourished. These pollen tubes continue to elongate by growth and pass down through the conducting tissue of the canal of the style, and thus reach the ovary where the seed is formed."

If a toothpick is used never use it for more than one kind of pollen. By allowing the camel's hair pencil to stand in an 
open mouth vial of alcohol a few moments after using, it may when dry be used upon another variety without fear of the former operation affecting the present.

Pollenizing should be done on bright, sunny days as far as possible. In wet weather a dry, warm house can be utilized and the work continued each day, provided sufficient pollen is at hand. On bright days pollen is generally very abundant, and may be collected, stored in vials and labeled ready for use. If kept perfectly dry this pollen will retain its vitality throughout the chrysanthemum season.

After fertilization give the plants only sufficient water to keep them from wilting. Always keep a record of the work, showing the parents of the seedlings. It will afford pleasure to know how a meritorious variety was produced, and may suggest possibilities along other lines.

Seeds ripen in five or six weeks. Those fertilized early in the season give the greatest number of seeds, doubtless due to more firvorable weather at that time. Do not anticipate super-abundance of seed. The crosses which give but few seeds generally produce the hest seedlings. Hand pollenized seeds are of more value than those naturally fertilized. It at least seems rational to expect more from seed secured by the union of our best kinds than from that produced by the wind without intent, or the bee whose only object is to secure his daily sustenance. If this be true, our results depend upon the degree of intelligence employed in the selection of parents, and thoroughness with which every detail is attended.

Seedlings.-The seeds should be sown in light soil as soon as they are ripe, using pots, pans or shallow boxes. They should be covered lightly and kept in a temperature of about 60 degrees, until they have germinated. If kept in so high a temperature the seedlings are (quite apt to damp off, and at the first indication of such a condition move to a more airy place. As soon as they have made their second pair of characteristic leaves, prick off into shallow boxes, planting about an inch apart. When showing signs of crowding 
they should be potted separately and repotted as often as necessary or planted into the bench, same as standard varieties.

They flower the first year from seed and there is nothing more interesting than to look over a large lot of seedlings and note the diversity of color and form. After the planted seedlings are established we nip out the top and allow two breaks to come up and flower, and as far as possible select a crown or early bud on one of these, and terminal or late bud upon the other; thus we gain some knowledge the first year as to which bud produces the best flower. Those that are considered desirable may be saved and given further trial.

Sports.-The word "sport" in connection with chrysanthemums refers to varieties which originate from bud varieties, and are termed "sports." Occasionally a variety will sport the first or second year after its origin from seed, but generally it does not take place until several years have elapsed, and then often simultaneously in remote localities. This has occurred in this country, the most marked case being that of Mrs. J. Jones, sporting to yellow. As a rule most of the whites sport to yellow, and pinks to white, although Viviand Moral gave us a sport variety, Chas. Davis which is bronze, and has also sported to white in the variety Mrs. Ritson. Louis Boehmer, magenta pink, sported to white and named L'Enfant des deaux Mondes. This variety sported under French rultivation to yellow and is known as Leocadie Centils. Louis Boehmer, the original variety, has given us several other sport varieties, such as Wm. Falconer, light pink; Mrs. (. B. Freeman, bronzy yellow, and Beauty of Truro, brouzy cerise. It is worthy to note that many varieties have chauged their color in this way many times, while others that are now very old have never shown any inclination to bud varieties. The yellow varieties seem less inclined to sport than other colors, possibly this is due to the fact that yellow is the original color of chrysanthemums.

Philadelphia, a light yellow, gave a sport several shades darker, and is kuown as Penusylvamia. It need not surprise anyone cultivating chrysanthemums to notice a plant producing flowers of two distinct colors. Sometimes the sport flowers will 
be one-half the original color, and again possibly on the same plant another bloom will be the new color entire.

It has been reported that flowers sometimes sport in form, that is, give a flower of entirely different form from that originally possessed, such as an incurved flower sporting to a reflexed form. Such cases are at least few and far between, in fact we are inclined to disbelieve that such changes have really taken place. Cultural conditions often change the form of flowers materially, also buds selected, and doubtless some of the cases reported were simply due to these causes.

To perpetuate the new color of the plant that has sported the method generally followed is to cut out the leaf on the flowering wood with a heel or portion of stem and place these under a bell glass or closed case to induce them to make roots after which they send forth new growth. These are planted the next season and if any possess the original color they are discarded and those of the new color saved. Generally in the course of two or three seasons it is safe to consider the new variety established and color fixed, as it is termed.

\section{CHAPTER XIII.}

PREPARING EXHIBITS.

Some time previous to the flowering season suitable boxes shnuld be made ready. Also material necessary for packing and stagring, such as cleats, excelsior, paper for wrapping and lining cases, labels for plants and cut blooms, and exhibitors cards. This will save some anxiety at the last when so many details require constant attention.

Plants.-All pots should be washed clean before packing, and each plant securely staked and tied, thoroughly watered, and plainly labeled. Where specimens and staudards are to be exhibited, the intervening spaces between the blooms should be filled with crumpled tissue paper to prevent shifting and rubbing against each other. With a strong cord draw the plant together as close as possible without injury. 
If they are to be transported a short distance and the weather is favorable they may be taken as they are. For long shipments that will be six or more hours in transit provide each plant with a frame work, around which paper can be wrapled to keep the blooms clean. Should there be danger of frecying, cotton wadding or several thicknesses of paper will be necessary.

Single stemmed plants are usually shipped in boxes the height of the pots with a post in each corner extending a little above the plants to which strips are nailed horizontally to form a rigid framework. The spaces between the pots are tucked with excelsior and the flowers wrapped with tissue. The frame is then covered with paper or other material as necessity demands.

Cut Flowers.-Blooms that are likely to be too far advanced for the exhibition should be cut and stored in water in a cool cellar with some light, (in total darkness the foliage soon turns yellow, cutting off a small portion of the stem and giving fresh water every three days. In this way they may be kept two or three weeks in a very presentable condition.

All blooms should be cut and stored in water at least 12 hours before packing and longer if possible. This allows them to take up sufficient water to harden the foliage and petals. In brighter weather it is best to do the cutting early in the day while they are firm.

The most suitable sized box for packing depends upon the size of the blooms, number to be packed, and required length of stems when staged. They must be of sufficient depth so that the cover when nailed does not crush the blooms. When large exhibits are to be handlerl, boxes 6 feet long, 2 feet wide, and 10 to 12 inches deep or thereabouts are the most serviceable.

The box is first lined with paper to exclude air, and if cold enough to protect from frost. The next step is to consult the schedule, sorting out each entry so they may be packed by themselves. If no one accompanies them to attend to the staging, each class should be divided with a sheet of paper and 
plainly marked, giving class number so that the person in charge will know each entry at a glance.

Each bloom should be labeled with a white card plainly written. A very suitable size for this purpose is $13 / 4$ by 4 inches, which should be tied to the stem near the bloom. A few extra blooms should be added in case some are injured in transit and the packer will have to use his judgment as to how many are required, by their present condition and apparent substance. Where the entries require a large number of blooms it is adviseable to label these, even though they are to be accompanied with someone who has a thoroligh understanding of unpacking and staging, as it saves much time and confusion at the last moment when everyone is exerting every effort to be through at the alloted hour.

IIake roles of excelsior wrapped with paper $21 / 2$ or 3 inches in diameter, and as loug as the box is wide. Sheets of tissue paper large enough to cover the blooms should be cut on one side to the center, and having the blooms near at hand all is ready. It requires two persons to pack to advantage, one placing the blooms in the box and attending to cleating, and a helper tying on the labels and holding the blooms while being wrapped. Beginuing at one end of the box place a roll of excelsior 6 or 8 inches from the end. The helper takes a bloom and holding it head down the packer slides the cut tissue paper around the stem, draws the edges downward giving the corners a few turns with the thumb and finger to keep in position.

It is difficult to say how tight the blooms should be wrapped, much depends upon their form and condition. Those of the reflexed type, like Viviand Morel and Yanariva, may be rolled moderately close without injury, while such varieties as Mrs. H. Robinson and Col. D. Appleton, should be given a little more freedom. After a little experience the packer will determine at a glance how tight they should be rolled.

It is then placed in the box allowing the neck of the flower to rest on the roll of excelsior, the object being to prevent outer petals being bruised. It is wise to select the largest blooms for the end of the box. This operation is repeated until the first 
row across the box is completed and the packing is continued in the same manner until the third row is tinished, which is fastened secure by a wooden cleat, pressing the stems down firm enough so they cannot shift.

If the weather is warm or the exhibit to be transported a long distance sprinkle the foliage well and cover with a few thicknesses of newspapers that have previously been saturated with water. The aim is to keep the foliage wet and the blooms dry. Continue the packing until the last row of blooms covers about one-third of the box and then begin in the same manner at the other end of the box.

Foreign Shipments.-Flowers grown in this country have been exhibited in England and visa versa. The directions given for packing are practical in such cases, but would suggest the stems being cut not to exceed 12 inches in length, and use Kift's Rubber Capped Flower Tube for each specimen. These tubes are glass vials with a tight fitting rubber cap which confines the water to the tube and thus the supply is sufficient to keep them fresh.

Another method is sometimes employed in which the flowers are packed so they stand upright, a very good system where the exhibit in not very large, or the distance to be shipped very long. The size commonly used is 3 by 4 feet and $2 \mathrm{ft}$. 6 inches in depth, but should the schedules require longer stems a deeper box will be necessary. These boxes are provided with cleats, one a few inches from the bottom and the other placed so as to come directly under the bloom. In packing put two cleats in position at one end of the box and after the blooms have been wrapped set them in position and tie securely, top and bottom.

As soon as one row is completed another set of cleats are adjusted and the work continued. The ends of the stems may be wrapped with sphágnum moss or inserted with rubber capped tubes filled with water to keep the foliage from wilting. Packed in this manner the foliage dries out more then when laid flat in the box owing to the large amount of air space, hence the necessity of providing moisture at the end of the stem to prevent flagging. These boxes are generally constructed 
with a hinge cover, also one side or end hinged from the middle so that the upper portion may be let down, making it more convenient in packing and unpacking.

Diessing Flowers.-This is resorted to somewhat by foreign exhibitors, but little practiced in this country. In fact most schedules prohibit dressing. The Incurved section requires more attention than the Japanese when this operation is resorted to. The method is simply to remove short or deformed petals and arrange perfect ones to occupy their places, also to separate those which have grown one into the other to form a regular rounded flower when finished. Sometimes semi-incurved Japaneco are dressed to give them a reflexed appearance. As far as known about the only dressing done in this country is the removal of deformed petals, which are likely to occur in any of the types. Very often strap-petals will appear in the cushion of the Anemone varieties and thus detract from their appearance, and should be removed with a pair of tweezers.

Staging Plants.-In arranging plants for exhibition much depends upon the schedule which should be thoroughly digested to conform with the rules and regulations. Then consider space allotted and if next the wall to be viewed from one side only, the tallest plants should be put in the background and others graduated to the shortest in front.

If the exhibit contains more than one color this should be considered and arranged for best effect. Groups for the center of the hall are arranged on the same plan, but such exhibits are viewed from all sides and will require greater effort to bring out uniformity.

In France the space allotted to plants is covered with light soil, into which the pots are plunged and the earth covered with green sod. In this way they have the appearance of being permanently planted, which adds greatly to the attractiveness of the exhibit.

Streging Blooms.-Collections of cut blooms are generally shown one in a vase, arranged on tables usually at the side of the hall so there is but one congregational side. Such tables 
will accommodate three rows in width and after the rases or glasses are so placed the blooms are arranged so the middle row will be slightly elevated above the first and the back row above the second. The object is to have each bloom show distinctly both its size and form. The largest ones should be placed in the back row and the smallest in front. When place ${ }^{3}$ in this manner they appear to be nearly all of a size. The light and dark colors should be alternated as much as possible for best effect.

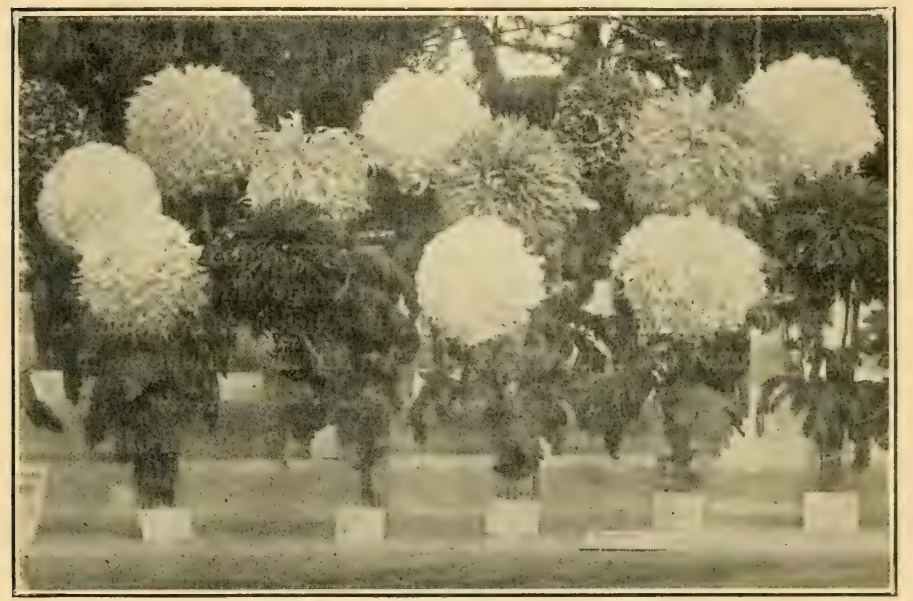

Fig. 18. A collection properly staged.

If there are restrictions as to length of stems this must be considered at the beginning, but if left to the discretion of the exhibitor ten or twelve inches for the first row will be about right, and three to six iuches longer for each of the successive rows according to the depth of the bloom. See Fig. 18.

The foregoing rule is practical where the tables are of regulation height, about $2 \mathrm{ft}$. $7 \mathrm{in}$., but if only a foot or so from the floor it will hardly be necessary to make auy distinction as to length of stems, inasmuch as the exhibit wlll be viewed from 
above. When the tables are built terrace-fashion the stems may be nearly or quite the same length.

Boards.-The board system used in England for staging collections is seldom used or little known to American exhibitors. It consists of a board $18 \times 24$ inches nailed to end pieces so that the front wlll be three and the back six inches above the table and are painted green. Holes are bored to accommodate twelve blooms, three rows front to back. The petals of each bloom are supported by a funnel-shaped cup terminating with a tube into which the stem is inserted and when properly adjusted a wedge is crowled between tube and stem to hold securely. The stem and cup tube are passed through the hole in the board into a tube containing water.

At the Kansas City show of 1902, mossed banks were substituted for the typical boards. These were constructed by nailing 6 -inch boards running lengthways of tables to scantling. The boards were placed far enough apart to admit the neck of a bottle and the back elevated to give a slope of about 3 inches to the foot. Bottles were placed proper distances apart and the whole framework covered with green moss. This system is very practical where large collections are to be staged.

Vases.-Classes calling for more than one bloom of a kind are generally staged together and may vary in number up to 100. When three to six are required, 18 to 24 inches are considered sufficient length of stem; twenty five to fifty, 3 to 4 feet. and vases of one hundred will need 5 feet or more for those occupying the center. In arranging vases of twenty-five or more the aim is to have each bloom show distinctly and the general appearance as symmetrical as possible.

When the schedule states "arranged for effect," colors which harmonize are considered best, such as white and pink, or yellow, bronze and red. Sometimes a few of the Anemone section may be used to advantage in such classes giving diversity in form. 


\section{CHAPTER XIV.}

EXHIBITIONS.

The Munagement.-The annual exhibition requires mental and physical as well as financial support and is generally more successful when backed by a strong organization. Very few exhibitions are certaiu of being successful year after year, particularly from a financial standpoint. Unvavorable weather is likely to impair the attendance and some other local attraction may divert the public.

Such organizations should appoint committees to handle certain parts of the work, such as arranging and mailing a schedule, music, advertising, and as the date of the show draws near supplement committees for decorating the hall, etc. The preliminary, or if possible complete schedule, giving the principal classes, should be mailed in January.

Make them definite, for example: best twenty-four blooms white, three varieties, stems not less than 36 inches, shown in one vase. Best twenty-five plants, tive varieties, grown to single stem and bloom in five-inch pots, not exceeding 30 inches above pots. When so arranged the manager is not hampered with questions. The exhibitor knows just what is required, and the judge has but one thing to consider,-quality.

The larger the premium the strouger the competition. Big prizes and honor of winning same are incentives which are farreaching and should be duly considered for sake of display. This course is a greater necessity in localities remote from the center of chrysanthemum cultivation, which is probably between Cleveland and Pittsburg.

If a final or complete premium list is issued it should appear a few weeks before the date of the show and may be arranged to serve the purpose of a program and thus curtail expense. The advertising is an important feature and the press should be furnished with short items of interest to the public that will also refer directly to the exhibition. If possible they should be supplied with photographs of intended exhibits and descriptions of same. A month prior to the date posters and other forms of advertising will be necessary. 
It is of great importance to have a competent secretary, as much depends upon accurate record of entries, premiums, etc. IV. N. Rudd, Mt. Greenwood, Ill., in his able article, "The Management of the Exhibition," read before the recent meeting of the American Carnation Society, suggests the following for the accounting department: "The writer prefers the De La Mare system of exhibition accounting, as being simple, speedy and accurate. It consists of an exhibitor's book, a class book, a judge's book, entry cards and envelopes for them, a set of gummed labels of different colors, 'first premium;' 'second premium,' etc., to be attached to entry cards by the judges as they complete each class."

The person best suited to act as superintendent or manager, should be selected and have full charge of all materials pertaining to the exhibition from the first day until the hall is vacated. From the schedule he will know about how much space will be necessary for the various classes, and if wise will study the hall carefully, mapping out where each class and group shall be staged. It will also be his duty, unless left to a committee, to provide suitable tables and vases and other requisites necessary. The vases should be of suitable size to accommodate the various classes, but should be uniform in each specific class so that one exhibitor has no advantage over another. These should be filled and if possible placed ready for use, on or before the opening day to avoid confusion and delay.

Provide new features each year as the public are constantly looking for something novel.

Prearrangement is an important factor to well conducted exhibitions. Details that can be arranged prior to the opening will save the manager much anxiety at the last moment, and whatever facilitates his work will assist the exhibitor and the task of judging will be less laborious.

The Jurlge.-In selecting a judge it should be a person having sufficient experience to be fully competent, and whose honor and integrity are above reproach. One to three judges are the number generally used, sometimes in large exhibitions where there are many classes to consider a greater number are 
pressed into service and divided into sets, each set being al. lotted certain classes. When so arranged the awards are made with the least possible delay.

The Chrysanthemum Society of America has adopted scales for judging which define the important qualifications to be considered in the various classes. They are as follows:

A.-Scale of points for bush plants and standards, single specimen or any number up to six, in an exhibition where the class under consideration does not form the chief feature in the exhibition hall.

Equality of size and form of plant ......... 40

Size of bloom..................... 35

Foliage .......................

Total .......................... 100

B.-Scale of points for bush plants, exhibits of more than six or for any number of specimen plants in an exhibition where the class under consideration forms the chief feature in the exhibition hall.

Equality of size and form of plant .......... 35

Size of bloom ........................ 40

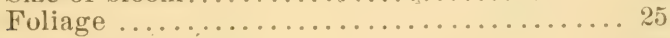

Total ............................ 100

C.- Scale of points for plants grown to single stem and one bloom. A height of not over three feet is recommended for plants in this class, and pots not over six inches in diameter.

Compact sturdy growth .............. 40

Foliage ........................... 30

Size of bloom ..................... 30

Total...........................

D.-Scale of points for specimen blooms.

Color ............................. 25

Form ....................... 25

Fullness ....................... is

Stem and Foliage................... 10

Substance ........................ 10

Size............................ 15

Total............................ 
E.-Distinctiveness.

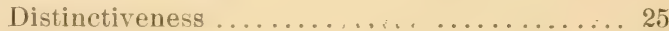

Form ...................... 15

Color ............................ 15

Size........................... 15

Stem ......................... 10

Foliage ........................ 10

Fullness ..................... 10

Total ......................... 100

To apply these scales understandingly they should be carefully studied, determining the important factors and these fully considered to determine the exhibit possegsing super-excellence. In scale D, there are six qualifications viz.: color, size, fullness, substance, stem and foliage. The color should be clear and positive whatever it may be. There is no form which could be considered perfect for all the varying types. Each possens specimen which are ideal as far as their particular class is concerned. Blooms having the greatest depth would have preference to those that are shallow, not only in quality of form but size. Size is easily determined and can be decided upon without great effort.

Fullness refers to the number of petals, hence those showing a disc or eye would be considered deficient in this respect.

Substance deals with the texture of the petals and those which are soft and flahby should he secondary to those possessing a firm texture.

The stem should be straicht, of wood length and stiff enough to properly support the bloom. The foliage should be luxuriant of good color and well up to the bloom. It is not always necessary to use scales in judning, as often the contrast of competitive exhibits are so pronounced that awards can be made with but little consideration. Where competition is close it is well to keep the important factors in mind, and if necessary use them.

Scale D and E are soon to be revised and it is hoped they will be made public early enough to be used the coming season. 
The Exhibitor.-A practical exhibitor knows the importance of thoroughly understanding the rules and regulations as well as the schedule of the exhibition in which he is to compete, and generally masters these prior to the date. In classes which specify certain colors such as white, pink, yellow, etc., it is advisable to select a variety that is most perfect in this respect, avoiding those that are shaded or marked with other colors. Never be confident of success before your blooms are staged or at least until you have seen those of your competitors.

Remember that judging to a certain degree is based upon individual preference and julges, like others, do not all see the same. The decision may be at a variance with your opinion, but whether right or wrong do not abuse the judge, or criticise his actions too severely. If you are satisfied there is something radically wrong and your exhibit has not been given just consideration, enter a protest. This should be made in writing, setting forth the grounds of your grievance. Sign and hand to the secretary to lay the matter before the judge.

Abide by the rules and regulations and never resort to trickery of any kind to gain a point. Such a course cannot succeed long at best, and it would be humiliating to have an exhibit disๆualified.

\section{CHAPTER XV.}

TYPES ETC.

Chrysanthemums possessing certain characteristics of form and petalage are grouped into classes, according to these peculiarities.

The following are aloridged descriptions of various types as adopted by the National Chrysanthemum Society of England:

Incured.-The distinguishing characteristics are the glohu lar form and regular outline of bloom. They should be as near a glole as possible, the florets broad, smooth, rouncled at the tips, and regularly arranged. A hollow center or eye, or uneveness of outline is a serious defect. 
Japanese Incurved.-No definition can be given to include all the remarkahle rarieties found in this type. The florets are either flat, fluted, yuilled or tabulated and of rarying length, from short, straight, and spreading, to long, drooping, twisted or irregularly incurved.

Huir\%-The chicf peculiarity consists of a covering of short glandular hairs on the reverse of the florets. This hair-like growth is shown to best advantage where the florets are incurved.

Reflexed.-The flowers should be perfectly circular in outline, without a trace of thinness in the center, hemispheroidal and with broad overlapping florets.

Large Anemones.-The characteristics are large size, high, neatly formed centers and regular arranged florets, one quilled and forming the center of disc, the other flat and horizontally arranged, forming the border or ray.

Japanese Anemones.-These are remarkable for their large size and fantastic form. The disc is more or less regular in outline while the ray florets vary in length, breadth and arrangement. They may be narrow and twisted, broad and curled, or droop, forming a fringe in some instances.

Pompons.-Small blooms, dwarf. growth and small leaves distinguish the true Pompons. The blooms are somewhat flat or nearly globular, averaging $1 \frac{1}{2}$ inches in diameter; neat, compact with short, flat, fluted florets.

Pompon Anemones.-These, in style of growth and size, are similar to the Pompons. They are really small flowered Anemones, having a center or disc of quilled and more or less regularly arranged ray florets.

Single.-These may be any size and form but should not have more than a double row of ray florets and arranged sufficiently close together to form a dense fringe. This section is divided into two classes known as the large and small flowering.

The National Chrysanthemum Society of England in their last official catalogue have added the following sections: 
Early Floucring Futioties. - (A) Large tlowering fapanese, (B) Pompons.

Spidery, Plumed, Feathery and Funtastic.

Market and Decorative in three sections, viz.: early, midseason and late.

Identifying. - Each year tlowersare sent to experts for identification, but very few understand how difficult it is to identify them when received in poor condition. Possibly the recipient has been looking at perfect flowers and the specimens received are entirely different, as to size, color and other qualifications. Foliage is often the surest means of identitication and in submitting samples do not fail to send a few leaves with each specimen.

If shipped by express see instructions for packing flowers, page 65. If sent by mail wrap each bloom with tissue paper and line the box with wax paper to prevent evaporation, and see that the box is of sufficient strength not to be crushed.

Each bloom should be numbered and a record kept so they can be reported upon in like manner.

The conditions under which Chryanthemums are grown are so varied and the blooms themselves so distinct that this task is very difficult and often fruitless:

\section{SELECTION.}

When viewing the exhibition table, notes are made of the best varieties to be grown the following seasun. In making these selections it is wise to consider which are most suitable for the desired purpose. The two chief classes are commercial and exhibition--the former should be subdivided as follows: first, where the product is packed and transported to the market and often repacked and reshipued before they reach the consumer; second, those produced for local consumption.

In the first instance those possessing pleasing colors, such as white, pink and yellow, good substance, incurved form and long strong stems with clean foliage are the most desirable.

Those growing for retail trade "an include many others for' sake of variety. Sume of the artistic formed sorts, like Iora, a 
few Anemones, and Pompons, will add materially to any form of arrangement from an artistic point of view.

The exhibition varieties may also he divided as follows: first, those for collections which are staged singly, and second, those for vases of twelve or more to be staged collectively.

Size is of most importance for collections and as the stems usually do not exceed 16 inches in length, are not so important provided they are strong enough to hold the flowers in an upright position.

For vases, size and colors, superlative in their respective classes are the most important factors. Strong, sturdy stems, well clothed with foliage are most effective and should be taken into consideration.

Many varieties suitable for the commercial grower are equally serviceable for exhibition. Each grower must consider his needs, if the demand is for medium rather than large blooms, it is best to inspect the varieties grown on a commercial place, or rely on the judgment of those who give this matter their constant attention.

Commercially the foreign varieties have met with little faror, as will be seen by referring to any list recommended for this purpose.

They generally require greater attention to produce marketable flowers, than those of American origin. In this country the great demand has been for good commercial sorts and the hybridizer has selected with this in view, while foreign seedings possessing superior "xhilitions qualities are most popular.

Do not discard those which do well under your method until experience has thoroughly demonstrated the merits of the newcomers.

Novelties should be tested from year to year, retaining those which show adrancement, bearing in mind the dmerican varieties are best for commercial growers and the importations should be carefully considered for exhibition. 


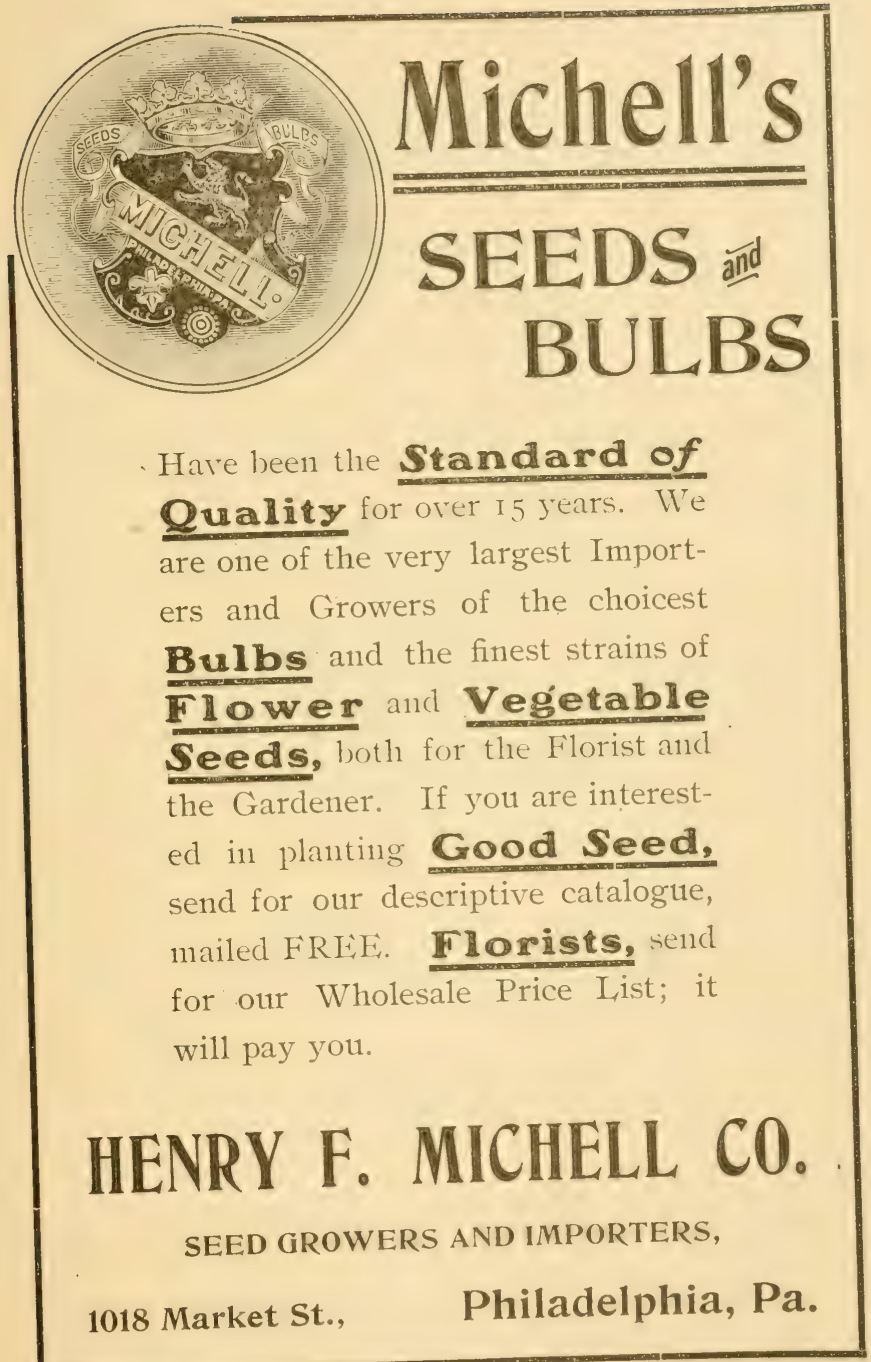


To keep in step with

the march of progress,

read the notes on the

\section{CHRYSANTHEMUM}

By BRIAN BORU

which are a regular feature of

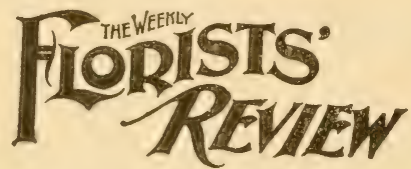

CHICAGO

"The Business Paper"

(For the Trade Only)

$\$ 1.00$ PER YEAR

Best Cultural Matter.

Accurate Market Reports.

Hence

The Best Advertising Medium. 


\section{GREENHOUSE}

\section{LUMBER}

\section{We Desiǵn Houses}

To meet their cultured requirements, using only the very best highest grade of GULF CYPRESS in their construction,

the grower thus gets

\section{The Very Best House}

or Range, for his special purpose, and location. If you contemplate building, write us. PLANS AND ESTIMATES FREE.

\section{HOT-BED SASH}

Cedar Posts, Bench Material Etc., Etc.

Lockland Lumber Co. Lockland, $O$. 
The book which you now hold in your hand, viz.: "SMITH'S CHRTSANTHIMIUM MANUAL," page 72 , gives a valuable pointer as to exhibition accounting and an unsolicited endorsement of what is therein styled the "De La Mare System."

\section{Systematic}

\section{Bookkeeping}

At the

\section{Flower Show.}

The clerical work of every flower show exhibition should be run on business lines. Our system is the best, the simplest, the least expensive, and, in every particular, the most satisfactory.

We have devised, for the use of Nanagers and Secretaries of Exhibitions, a set of Account Books, covering in detail the orderly and systematic arrangement of every item in bookkeeping, from the time the Entry Forms are given out to the payment of prizes and closing up of accounts, and this system is so concise and complete that prize-winners can be paid off without confusion immediately after the Judges' decisions have been rendered.

This System, once tried, is ever a favorite. It can be truthfully called the greatest Labor-Saver ever placed within the reach of Exhibition Managers.

Descriptive circulars and samples of books will be mailed promptly on application to

A. T. De La Mare Ptg. \& Pub. Co. Ltd. P. O. Box, 1697, New Yoxk. 


\title{
"Excellent Service"
}

\author{
from the
}

\section{Morehead Return Trap}

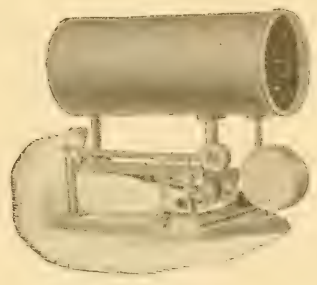

Detroit, Mich., 3-12-'04.

Messrs. Nathan Smith \& Son, Adrian, Mich.

Gentlemen:-We would appreciate from you an expression of your opinion with regard to the Morehead Trap for greenhouse work.

Adrian, Mich., 3-14-'04.

American Blower Co., Detroit, Mich.

Gentlemen:-In reply to your favor of the 12 th inst., we are pleased to state the Morehead Trap installed in our greenhouse in 1901 has done excellent service and required no attention whatever. We most heartily endorse and recommend it to everyone requiring the use of a steam trap.

(Signed) Nathan Smith \& Son.

For particulars and prices, address

American Blower Company DETROIT 


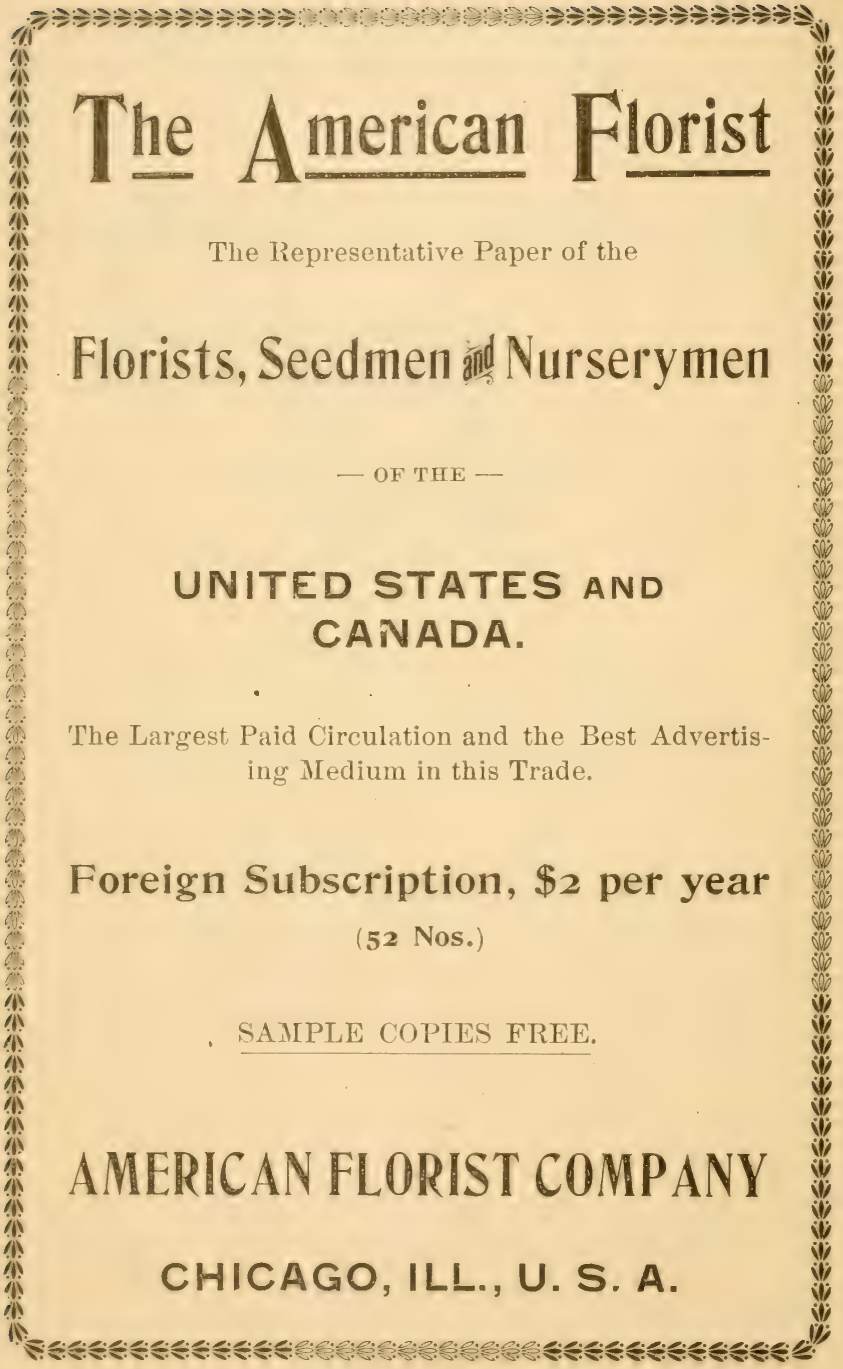




\section{Description of our \\ Double Arch Carnation Support.}

This support is giving satisfaction wherever used. After trying very near every other mehod in use, we have come to the conclusion that this support is the best and cheapest.

\section{Its Chief Advantages are:}

1. Its cheapness.

2. The ease with which it can be set, or taken down and stored.

3. Being held rigid by overhead wire, the support is not easily displaced.

4. The plants are never crowded but kept in a free, natural position.

5. The flowers can be cut on any length stêm without disarranging the support.

6. The bed can be watered without wetting any part of the plants.

7. A free circulation of air can always be maintained, thereby checking diseases.

8. As the arches are made from the very best galvanized wire, they are practically non-destructible.

The following quotations are per 100 Arches, and it requires two of these to support each plant: No. 11 ll ire, hent ready for use, $\$ 1.15$ per 100 . No. 9 Wire, bent ready for use, $\$ 1.30$ per 100 . F. O. B. Adrian. In making order, state plainly whether rou are referring to arches or the complete sup= port, as it requires two of the former. to make one of the latter.

The above quotations are subject to change without notice, as price of wire fluctuates continually.

After careful tests we find that the 25 inch stake is the best suited for most varieties of Carnations. If shorter stakes than those quoted are desired, subtract 10 cents for every 3 inch deduction in length, and for longer stakes add 10 cents for every additional 3 inches.

Rose, Chrysanthemum, and other plant stakes, (ut to any length, will be quoted on application.

Send for illustrated catalogue.

\section{NATHAN SMITH \& SON Adrian, Mich.}




\section{Chrysanthemums and Carnations.}

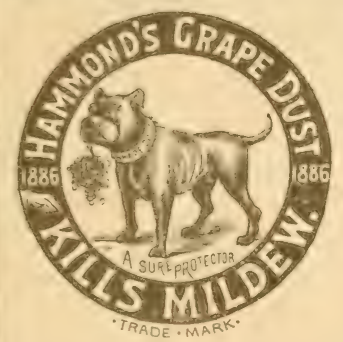

This came from Wallace Gomerall,. Superintendent of the famous "Wodenethe," owned and maintained by Winthrop Sargent, Esq., Fishkill-on-Hudson, N. Y.:

"For Chrysanthemums, we use Grape Dust with the best results by freely dusting with it until the delicate blooms come, then we are a bit shy of it to prevent any staining of the petals. but during the green state, even in bad weather, there is no trace of fungus, and we keep free of the spot. I have recommended it to many rardeners, and so far for my acquaintances have found it very valuable. In common with many Gardeners and l. lorists, I hare found it of great value in checking the Rust on Carnations. It is not expensive to use, for by using in air bellows it diffuses itself everywhere, and is, in my judgment, a valuable every day article." Grape Uust is sold by the seedsmen of America.

For I'amplelet, address B. HAMMOND, Fishkill=on=Hudson, N. Y.

\section{GREENHOUSE MATERIAL}

OF BEST QUALITY AND WORKMANSHIP.

Allow us to submit Designs, Sketehes and Estimates on your proposed Greenhouses, Conservatories and Horticultural Buildings.

\section{Use Foley Ventilating Apparatus.}

HOT BED SASH ready for PROMP'T SHIPMENT.

SEND FOR FREE CATALOGUE.

\section{FOLEY MFG. C0. 271 w w st. CHICAG0.}


BENJAMIN CHASE.

JOHN C. CHASE.

\section{WOOD LABELS}

IN EVERY VARIETY

....FOR....

NURSERYMEN AND FLORISTS.

$$
\begin{gathered}
\text { WIRED PRINTED } \\
\text { TREE LABELS } \\
\text { A SPECIALTY. } \\
\text { BENJAMIN OHASE, } \\
\text { DERRY, N. H. }
\end{gathered}
$$

A Complete Line of

Chrysanthemums,

Carnations, Cannas \& Geraniums.

Also, Hardy Herbaceous and Decorative Plants.

Correspondence Solicited.

NATHAN SMITH \& SON ADRIAN, MICH. 


\section{Chrysanthemum Society of America.}

The aims of this society are:

To increase the general interest in the cultivation of the Chrysanthemuin.

To improve the standard of excellence in the flower.

To improve the methods of cultivation and to increase its use as a decorative flower.

To properly supervise nomenclature and to keep a Registure of Seedlings in order to prevent duplication of names.

To stimulate the growing and introduction of improved seedlings in every legitimate way.

The annual report alone is worth more than the yearly membership fee. Any of the following officers will be pleased to give full particulars:

President-Arthur Harrington, Madison, N. J. Vice=President - Elmer D. Smith, Adrian, Mich. Secretary-Fred H. Lemon, Richmond, Ind. Treasurer-John N. May, Summit, N. J.

Next meeting and exhibition will be held at Boston, November 3 to 6 , 1904 . 


\section{FERTILENE}

Is composed of concentrated chemicals for making Mquid plant food.

A complete chemical fertlizen for chrysanthemums and other plants. For the past fifteen years we have used this preparation as a liquid fertilizer wholly, and doubtless our success is largely dide to this fact: The many prizes awarded us diwing these years ake pesmanent moikuments. Which impart more to hts recommendation than we can imply by words. FERTICENE contains the same constiter ents as those incorporated in manure and this contalns in. proper quantikies, nitrogen, potsisls and phosphoric acid, Which are the most indportant elements conducive to plant Hife.

Stable manure contains less than a per cent of food, While RERTULENE contains over 60 per cent actual plant foods.

The ad vantages of FERTIL ENB over other manures are:

It is clean.

It has no offensive odor.

It is soluable and thus easily prepared.

It. is lmmediate and permanent in its effect:

It is so highly concentrated that it is the cheapest.

It saves time and labor and gives accurate results.

\section{PRICE.}

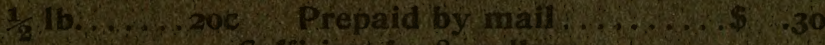
Sufficient for 80 gallons.

1.16. ...35c Prepaid by mail ........ .50 Sulficient for i6o gallons.

10 lbs. . . . . . .

Suffictont for 1600 gallons:

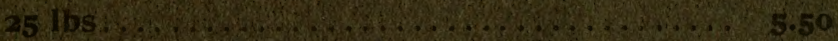
Sufficient for 4000 gallons: $5016 \mathrm{~s}$ Surficient for 8000 gallons. 10.00

Prepsired and sold by

NATHAN SMUTH \&S SON, Adrian, Mich. 
LIBRARY OF CONGRESS

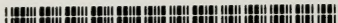

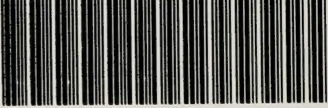
00009201774 